\title{
Inflation Persistence, Fiscal Constraints and Non-cooperative Authorities: Stabilisation Policy in a Monetary Union*
}

\author{
Tatiana Kirsanova ${ }^{\dagger}$ \\ Mathan Satchi ${ }^{\ddagger}$ \\ University of Exeter \\ University of Kent \\ David Vines ${ }^{\S}$ \\ Balliol College, University of Oxford; \\ Simon Wren-Lewis $₫$ \\ University of Exeter \\ Research School of Pacific and Asian Studies, \\ Australian National University; and CEPR
}

February 14, 2005

\begin{abstract}
This paper investigates the importance of fiscal policy in providing macroeconomic stabilisation in a monetary union. We use a microfounded New Keynesian model of a monetary union which incorporates persistence in inflation, and examine non-cooperative interactions of fiscal and monetary authorities. We find that particularly when inflation is persistent, the use of fiscal policy for stabilisation can significantly improve welfare over and above that which arises through the working of automatic stabilisers. We conclude that a regulatory framework for fiscal policy in a monetary union should allow a role for active fiscal stabilisation.
\end{abstract}

Key Words: Optimal monetary and fiscal policies, Monetary union, Asymmetric Shocks JEL Reference Number: E52, E61, E63, F41

${ }^{*}$ We are grateful to Christopher Allsopp, Andy Blake, Stephen Hall, Ray Barrell, Brian Henry, Kalin Nikolov, Martin Weale and Peter Westaway for very helpful comments and suggestions, and to the Leverhulme Trust for financial support under grant no. F/108 519A, "EMU and European Macroeconomic Policy in a Global Context."

${ }^{\dagger}$ address: University of Exeter, School of Business and Economics, Streatham Court, Rennes Drive Exeter EX4 4PU; e-mail: t.kirsanova@exeter.ac.uk

${ }^{\ddagger}$ Address: Department of Economics, Keynes College, University of Kent, Canterbury, CT2 7NP; e-mail m.satchi@kent.ac.uk

$\S$ address: Department of Economics, Manor Road Building, Manor Road, Oxford, OX1 3UQ; e-mail david.vines@economics.ox.ac.uk

^address: University of Exeter, School of Business and Economics, Streatham Court, Rennes Drive Exeter EX4 4PU; e-mail: s.wren-lewis@exeter.ac.uk 


\section{Introduction}

In this paper we examine the potential for national fiscal policy to help stabilise individual economies within a monetary union. While the vulnerability of monetary unions to asymmetric shocks is well known, there has been surprising little analysis of the extent to which fiscal policy can overcome these problems within the framework of the new international macroeconomics (see Lane (2001) for a survey). This is despite the fact that policy makers in potential members of the European Monetary Union have actively discussed the possibility of using fiscal policy in this way (Treasury (2003), Swedish Committee (2002)).

One advantage of using a model with clear microfoundations is that we can directly compute welfare, using either a traditional loss function or a measure explicitly derived from agents utility. While our analysis does not deal directly with some of the important political economy issues involved in using fiscal policy as a countercyclical tool (see e.g. Calmfors (2003)), it should help inform that debate. In particular, we investigate whether there is a significant welfare cost to restricting fiscal policy to keep deficits within certain bands, as in the Stability and Growth Pact.

\section{Private Sector Behaviour and Persistence}

Our analytical framework is close to that in a recent paper by Beetsma and Jensen (2004), whose model is in turn based on one developed in Benigno and Benigno (2000). They also look at the role of fiscal policy in a microfounded two-country model of monetary union. Our analysis is more general in two important respects. First, while their representative consumers are identical across countries (and therefore consume an identical basket), we allow for some home bias in consumption, along lines that are familiar, from Gali and Monacelli (2002), for example ${ }^{1}$. Second, while many papers embody nominal inertia in the form of Calvo contracts, we also allow for some additional inflation inertia, using a set-up outlined in Steinsson (2003). This not only makes our model more realistic ${ }^{2}$, but it also gives policy a greater potential role in influencing the dynamic response to shocks. We show that this additional inflation inertia can cause oscillatory dynamics, or even instability, so that a stabilising fiscal policy may become essential. ${ }^{3}$

\section{Welfare and Fiscal Constraints}

Our analysis of policy is designed to be normative. We evaluate outcomes on the basis of social loss derived from the utility of individual agents. There is a standard problem about how to avoid linear terms in such a measure of social loss. There are three common approaches to resolving this

\footnotetext{
${ }^{1}$ See also Duarte and Wolman (2002).

${ }^{2}$ See Mankiw (2001), Mehra (2004), Benigno and Lopez-Salido (2002) among many others.

${ }^{3}$ In some respects our set up is more restrictive than Beetsma and Jensen (2004): for example, we assume our two economies are of equal size while they do not.
} 
problem. Schmitt-Grohe and Uribe (2003), following Sims (2000), abandon the linear-quadratic framework and instead work with second-order approximations to the model equations. As an alternative, Benigno and Woodford (2003), Benigno and Woodford (2004), and Sutherland (2002) assume specific policy rules, which of themselves remove the linear terms ${ }^{4}$. However, for our purposes it is more convenient to take a third approach (as in Rotemberg and Woodford (1997) and Benigno and Benigno (2000) for example), where we assume the existence of an employment subsidy, financed by lump-sum taxation, precisely of the kind necessary to remove linear terms in the measure of social loss.

One of the difficulties of working with our rich model of private sector behaviour is that our microfounded measure of social loss will depart substantially from the objective function that policy makers are normally assumed to follow. In particular, it is quite complex (see below), whereas actual policy makers are likely to be guided by more simple objective functions. That is why for the monetary authority we assume a standard loss function, which penalises deviations of inflation from its target and of output from its natural rate. This captures the essential features of the remit likely to be given to a central bank. For the fiscal authorities we assume that the loss function not only penalises deviations in output and inflation (so that their fiscal policy supports monetary stabilisation), but also penalises deviations of the fiscal deficit from its equilibrium level. We find that the gains due to fiscal stabilisation are large (as measured by the 'true' social loss function) even when fiscal authorities are guided by such a simple loss function. These gains would be likely to increase further if fiscal authorities were to actually optimise 'true' social welfare.

We also follow the papers cited above in not extending the analysis to study the effects on government behaviour of a government solvency constraint; the focus here is on the short-run stabilisation of fiscal policy, assuming that this will not be restricted by solvency constraints. An analysis of solvency is left for future research.

\section{Non-cooperation in Policy Making}

We change the common assumption that fiscal and monetary authorities cooperate in pursuit of shared objectives. Instead of this we model a non-cooperative game, in which they have differing objectives. This provides a more realistic picture of monetary and fiscal interactions. Furthermore, allowing fiscal and monetary authorities to have separate objectives is necessary if we are to investigate constraints on fiscal stabilisation (in the manner discussed above), without at the same time altering the objectives of monetary policy.

We solve the policy game under monetary leadership. One reason for doing this is illustrated by a comparison with a single country, in which it is natural to think of the fiscal authority as a Stackelberg leader. Such a fiscal authority sets fiscal policy in the light of its understanding of how

\footnotetext{
${ }^{4}$ Sutherland (2002) imposes a form of policy which is too specific for our purposes, while Benigno and Woodford (2003), Benigno and Woodford (2004) impose a 'timeless perspective' on policy.
} 
the monetary authority will respond, in contrast to the monetary authority who sets interest rates in the light of its observations of fiscal outcomes without thinking strategically about how it might influence these ${ }^{5}$. By contrast, in a monetary union, the monetary authority is 'large', since it sets the interest rate for the union as a whole, whereas the fiscal authorities of the separate countries are 'small' in that each of them sets policy for only one country. That suggests that each of them is acting separately and will set their policy without thinking strategically about how its policy setting would influence monetary policy. Of course, they might cooperate and collectively lead the monetary authority. Our procedure involves us making the judgement that they are unlikely to do this.

Our approach is complementary to the one in Gali and Monacelli (2004), who consider many small countries in a monetary union. In their paper each country is small, and is subject to idiosyncratic shocks. We focus on big countries, subject to asymmetric shocks. We assume that although fiscal decisions are taken independently, there is a Nash set-up, in which each player is fully aware of the reaction function of other players. We follow Beetsma and Jensen (2004), in that our monetary union is not open to the rest of the world.

The paper is laid out as follows. Section 2 describes the theoretical structure of model. Calibration of the model is discussed in Section 3. The main results are presented in Section 4, and Section 5 concludes.

\section{The Model}

\subsection{The Setup}

Our monetary union consists of two economies, labelled $a$ and $b$. Each of these is inhabited by a large number of individuals and firms. Each representative individual specialises in the production of one differentiated good, denoted by $z$, and spends $h(z)$ of effort on its production. He consumes a consumption basket $C$, and also derives utility from per capita government consumption $G$. Private and public consumption are not perfect substitutes.

In each of the two economies the consumption basket consists of two composite goods, the domestic composite good (produced in the home country, denoted by $\mathrm{Ha}, \mathrm{Hb}$ ), the foreign composite good from the other open economy (produced in the foreign country, denoted $H b, H a$ ). Each composite good in turn consists of a continuum of produced goods $z \in[0,1]$. We also assume that countries $a$ and $b$ are identical in all their parameters. In order not to repeat symmetric equations, we will use the index $k$ for a single country in the union, $k \in\{a, b\}$, and use index $\bar{k}$ to denote the other country, i.e. if $k=a$ then $\bar{k}=b$, if $k=b$ then $\bar{k}=a$.

\footnotetext{
${ }^{5}$ Ref to UK
} 
Preferences of individuals are assumed to be :

$$
\max _{\left\{C_{k s}, h_{k s}\right\}_{s=t}^{\infty}} \mathcal{E}_{t} \sum_{s=t}^{\infty} \beta^{s-t}\left[u\left(C_{k s}, \xi_{k s}\right)+f\left(G_{k s}, \xi_{k s}\right)-v\left(h_{k s}(z), \xi_{k s}\right)\right]
$$

where we allow for taste/technology shocks $\xi$. Domestically produced goods may be consumed either at home or abroad and so:

$$
y_{k t}(z)=c_{H k, t}(z)+c_{H k, t}^{\bar{k}}(z)+g_{H k}(z)
$$

where the superscript $\bar{k}$ denotes the foreign destination of some goods. $g_{k}(z)$ is government consumption. We assume that the government in each country consumes the domestically produced good only, so $g_{H k}=g_{k}$.

All goods are aggregated into a Dixit and Stiglitz (1977) consumption index with the elasticity of substitution between any pair of goods given by $\epsilon_{t}>1$ (which is a stochastic elasticity ${ }^{6}$ with mean $\epsilon$ ):

$$
C_{H k t}=\left[\int_{0}^{1} \frac{\frac{\epsilon_{t}-1}{\epsilon_{t}}}{c_{H k t}}(z) d z\right]^{\frac{\epsilon_{t}}{\epsilon_{t}-1}}
$$

Every household consumes both domestic and foreign goods with the elasticity of substitution between them given by $\eta>0$. Therefore, the consumption basket in country $k$ is

$$
C_{k}=\left[\left(\alpha_{d}\right)^{\frac{1}{\eta}} C_{H k}^{\frac{\eta-1}{\eta}}+\left(\alpha_{n}\right)^{\frac{1}{\eta}} C_{H \bar{k}}^{\frac{\eta-1}{\eta}}\right]^{\frac{\eta}{\eta-1}}
$$

where the index $t$ is suppressed for notational convenience, $\alpha_{d}$ is the share of consumption of domestic goods, $\alpha_{n}$ is the share of consumption of goods imported from the neighbour country (the other open economy), $k \in\{a, b\}$.

\subsection{Demand: Optimal Consumption Decisions}

An individual chooses optimal consumption and work effort to maximise the criterion (1) subject to the intertemporal budget constraint:

$$
\mathcal{E}_{t} \sum_{s=t}^{\infty}\left(R_{t, s} P_{k s} C_{k s}\right) \leq \mathcal{A}_{k t}+\mathcal{E}_{t} \sum_{s=t}^{\infty}\left(R_{t, s}(1-\tau) w_{k s}(z) h_{k s}(z)\right)
$$

where $P_{k t} C_{k t}=\int_{0}^{1}\left(p_{H k}(z) c_{H k}(z)+p_{H \bar{k}}(z) c_{H \bar{k}}(z)\right) d z, \mathcal{E}_{t}\left(R_{t, s}\right)=\prod_{m=t}^{s-1} \frac{1}{1+i_{m}}, i_{t}$ is short-term interest rate and $\mathcal{A}_{k t}$ are nominal financial assets of a household, $k \in\{a, b\}$. Here $w$ is the wage rate, and $\tau$ a constant tax rate on labour income. In equilibrium we assume $\pi=0$.

\footnotetext{
${ }^{6}$ We make this parameter stochastic to allow us to generate shocks to the mark-up of firms.
} 
The household optimisation problem is standard (Woodford (2003)) and, after linearisation, it leads to the following first order condition for country $k$, written in terms of deviations from the steady state (for each variable $X_{t}$ with steady state value $X$, we use the notation $\hat{X}_{t}=\ln \left(X_{t} / X\right)$ ):

$$
\hat{C}_{k t}=\hat{C}_{k t+1}-\sigma\left(\hat{\imath}_{t}-\hat{\pi}_{k t+1}\right)+\hat{\xi}_{k t}-\hat{\xi}_{k t+1}
$$

where $\sigma=-u_{C}(C, 1) / u_{C C}(C, 1) C$ is the elasticity of intertemporal substitution.

The optimal allocation of any given expenditure within each category of goods yields the demand functions:

$$
c_{H k t}(z)=\left(\frac{p_{H k}(z)}{P_{H k}}\right)^{-\epsilon_{t}} C_{H k t}
$$

where $P_{H k t}=\left[\int_{0}^{1} p_{H k t}^{1-\epsilon_{t}}(z) d z\right]^{\frac{1}{1-\epsilon_{t}}}$.

The optimal allocation of expenditures between domestic and foreign goods implies:

$$
C_{H k}=\alpha_{d}\left(\frac{P_{H k}}{P_{k}}\right)^{-\eta} C_{k}, C_{H \bar{k}}=\alpha_{n}\left(\frac{P_{H \bar{k}}}{P_{k}}\right)^{-\eta} C_{k}
$$

where the consumer price index for country $k$ is:

$$
P_{k}=\left(\alpha_{d} P_{H k}^{1-\eta}+\alpha_{n} P_{H \bar{k}}^{1-\eta}\right)^{\frac{1}{1-\eta}}
$$

We define the terms of trade $S_{a b}$, the nominal exchange rate $E_{a b}$, and the real exchange rate $Q_{a b}$ as follows

$$
S_{a b}=\frac{P_{H b}}{P_{H a}}, E_{a b}=\frac{P_{H b}}{P_{H b}^{b}}, Q_{a b}=\frac{E_{b} P_{b}^{b}}{P_{a}} .
$$

\subsection{Supply: Pricing Decisions by Firms}

In order to describe price setting decisions we split firms into two groups according to their pricing behaviour, following Steinsson (2003). In each period, each firm is able to reset its price with probability $1-\gamma$, and otherwise, with probability $\gamma$, its price will rise at the steady state rate of domestic inflation. Among those firm, which are able to reset their price, a proportion of $1-\omega$ are forward-looking and set prices optimally, while a fraction $\omega$ are backward-looking and set their prices according to a rule of thumb.

Forward-looking firms are profit-maximising, they reset prices optimally, given Calvo-type constraints on price setting, that results in the following formula for $P_{H k, t}^{F}$, which for convenience is written in terms of log-deviations from the steady state (see Appendix A.1):

$$
\begin{aligned}
\hat{P}_{H k, t}^{F} & =\gamma \beta \hat{P}_{H k, t+1}^{F}+\gamma \beta \pi_{H k, t+1} \\
& +\frac{(1-\gamma \beta) \psi}{\psi+\epsilon}\left(\alpha_{n} \hat{S}_{k \bar{k} t}+\frac{1}{\psi} \hat{Y}_{k t}+\frac{1}{\sigma} \hat{C}_{k t}+\left(\frac{v_{y \xi}}{v_{y}}-\frac{u_{C \xi}}{u_{C}}\right) \hat{\xi}_{k t}+\hat{\eta}_{k t}\right)
\end{aligned}
$$


where $\pi_{H k, t}$ is resulting domestic inflation in country $k$.

The rule of thumb used by a backward-looking firm to set its price $P_{H k, t}^{B}$ is

$$
p_{H k, t}^{B}=p_{H k, t-1}^{r} \Pi_{H k, t-1}\left(\frac{Y_{k t-1}}{Y_{k t-1}^{n}}\right)^{\delta}
$$

where $P_{H k, t-1}^{r}$ is the average domestic price in the previous period, $\Pi_{H k, t}=P_{H k, t} / P_{H k, t-1}$ is past period growth rate of prices and $Y_{k t} / Y_{k t}^{n}$ is output relative to the flexible-price equilibrium. For the economy as a whole, the price equation can be written as:

$$
P_{t}=\left[\gamma\left(\Pi P_{t-1}\right)^{1-\epsilon_{t}}+(1-\gamma)(1-\omega)\left(P_{t}^{F}\right)^{1-\epsilon_{t}}+(1-\gamma) \omega\left(P_{t}^{B}\right)^{1-\epsilon_{t}}\right]^{\frac{1}{1-\epsilon_{t}}} .
$$

Following Steinsson (2003) and allowing for government consumption terms in the utility function, we can derive the following Phillips curve for our economy, written in terms of log-deviations from the steady state ${ }^{7}$ :

$$
\begin{aligned}
\hat{\pi}_{H k t} & =\chi \beta \hat{\pi}_{H k t+1}+(1-\chi) \hat{\pi}_{H k t-1}+\kappa_{c} \hat{C}_{k t}+\kappa_{s} \hat{S}_{a b t} \\
& +\kappa_{y 0} \hat{Y}_{k t}+\kappa_{y 1} \hat{Y}_{k t-1}+\left(\frac{v_{y \xi}}{v_{y}}-\frac{u_{C \xi}}{u_{C}}\right) \hat{\xi}_{k t}+\hat{\eta}_{k t}
\end{aligned}
$$

Coefficients $\chi$ and $\kappa \mathrm{s}$ are given in Appendix A.1 as functions of $\gamma$ and $\omega$ and other structural parameters. The constant labour income tax rate $\tau$ does not appear here because we have used the first order condition (see (16) below) to substitute for the equilibrium post-tax real wage. Although the constant wage income tax has no effect on the dynamic equations for log-deviations from the flexible price equilibrium, it alters the equilibrium choice between consumption and leisure for the consumer. The Phillips curve (14) has a structure in which both current and past output have an effect on inflation. Its specification is derived in Steinsson (2003) and we briefly repeat this derivation in Appendix A.1, where we explain our open-economy extension. In the case when all consumers are forward-looking, i.e. $\omega=0$, this Phillips curve collapses to the standard forwardlooking Phillips curve (see Rotemberg and Woodford (1997)). If, by contrast, all consumers use the rule of thumb in price-setting decisions, i.e. if $\omega=1$, this Phillips curve can be made to collapse into the form of an 'accelerationist' Phillips curve. The presence of the term of trade in the Phillips curve is due to the fact that people consume a basket of goods which includes imports but, of course, produce only domestic goods.

\subsection{The Economy as a Whole}

\subsubsection{Aggregate Demand}

Aggregate demand for country $k \in\{a, b\}$, is given by a linearised GDP identity:

$$
\hat{Y}_{k t}=\theta \alpha_{d} \hat{C}_{k t}+\theta \alpha_{n} \hat{C}_{\bar{k} t}^{\bar{k}}+(1-\theta) \hat{G}_{k t}+2 \theta \eta \alpha_{d} \alpha_{n} \hat{S}_{k \bar{k} t}
$$

\footnotetext{
${ }^{7}$ The derivation is identical to the one in Steinsson (2003), amended by the introduction of mark-up shocks as in Beetsma and Jensen (2003). A detailed derivation is given in Appendix A.1.
} 
The derivation of this formula is given briefly in Appendix A.2. The parameter $\theta$ denotes the share of private consumption in output, so that $1-\theta$ is the share of the government sector in the economy.

\subsubsection{Aggregate Supply}

The Phillips curve equation (14) contains terms in the preference shock $\xi$. These can be replaced by consumption, output and the terms of trade at their 'natural' levels (superscript $n$ ), which is the level of these variables that would occur in an economy with flexible prices and no mark-up shocks. Under flexible prices the real wage is always equal to the inverse of this mark-up, see Appendix A.1. Optimisation by consumers then implies (we assume the production function $y_{t}=h_{t}$ ):

$$
\frac{w_{k t}}{P_{H k t}}=\frac{P_{k t}}{P_{H k t}} \frac{v_{y}\left(y_{k t}^{n}(z), \xi_{k t}\right)}{(1-\tau) u_{C}\left(C_{k t}^{n}, \xi_{k t}\right)}=\frac{\mu^{w}}{\mu_{t}}
$$

where $\mu_{t}=-\left(1-\epsilon_{t}\right) / \epsilon_{t}$ is a monopolistic mark-up, and $\mu^{w}$ is the employment subsidy for producers. Linearisation of $(16)$ yields:

$$
\hat{Y}_{k}^{n} \frac{1}{\psi}+\hat{C}_{k}^{n} \frac{1}{\sigma}+\alpha_{n} \hat{S}_{k \bar{k}}^{n}+\left(\frac{v_{y \xi}}{v_{y}}-\frac{u_{C \xi}}{u_{C}}\right) \hat{\xi}_{k}=0
$$

\subsubsection{Financial Markets}

We assume complete capital markets with perfect capital mobility and thus a common nominal interest rate in the two countries.

\subsubsection{Putting things together}

We now write down the final system of equations for the 'law of motion' of the out-of-equilibrium economy. We simplify notation by denoting gap variables with lower case letters: for any variable $x_{t}=\hat{X}_{t}-\hat{X}_{t}^{n}$. We use relationship (17) to substitute out the $\xi$-shock term in the Phillips curve, which enables us to rewrite the dynamic system in 'gap' form. (We also substitute out for consumer price inflation in terms of domestic inflation and exchange rates.)

$$
\begin{aligned}
c_{a t} & =c_{a t+1}-\sigma\left(i_{t}-\alpha_{d} \pi_{H a t+1}-\alpha_{n} \pi_{H b t+1}\right) \\
c_{b t} & =c_{b t+1}-\sigma\left(i_{t}-\alpha_{d} \pi_{H b t+1}-\alpha_{n} \pi_{H a t+1}\right) \\
\pi_{H a t} & =\chi^{f} \beta \pi_{H a, t+1}+\chi^{b} \pi_{H a, t-1}+\kappa_{c} c_{a t}+\kappa_{y 0} y_{a t}+\kappa_{y 1} y_{a t-1}+\kappa_{s} s_{a b t}+\hat{\eta}_{a t} \\
\pi_{H b t} & =\chi^{f} \beta \pi_{H b, t+1}+\chi^{b} \pi_{H b, t-1}+\kappa_{c} c_{b t}+\kappa_{y 0} y_{b t}+\kappa_{y 1} y_{b t-1}-\kappa_{s} s_{a b t}+\hat{\eta}_{b t} \\
y_{a t} & =(1-\theta) g_{a t}+\theta \alpha_{d} c_{a t}+\theta \alpha_{n} c_{b t}+2 \theta \eta \alpha_{d} \alpha_{n} s_{a b t} \\
y_{b t} & =(1-\theta) g_{b t}+\theta \alpha_{d} c_{b t}+\theta \alpha_{n} c_{a t}-2 \theta \eta \alpha_{d} \alpha_{n} s_{a b t} \\
s_{a b t} & =\pi_{H b t}-\pi_{H a t}+s_{a b t-1}
\end{aligned}
$$

Equations (18) - (19) are the consumption equations for each country from (6), written in terms of domestic inflation. Equations (22) and (23) are aggregate demand equations from (15). Equation 
(24) follows from the assumption of the fixed nominal exchange rate between countries $a$ and $b$. From the system it is clear that cost-push shocks $\hat{\eta}$ are distortionary. The absence of terms in taste shocks shows that taste shocks alone have no impact on gap variables. However, as we show below, taste shocks do influence natural levels and therefore the size of the impact of cost-push shocks on welfare. The tax rate does not appear in the system because consumers are Ricardian.

\subsection{Behaviour of the Monetary Authorities}

The union central bank uses the short-term interest rate as a policy instrument. As discussed in the introduction, in this paper we study the welfare implications of conventional policymaking, rather than seeking socially optimal policy. We thus assume that the monetary authority seeks to minimise the following traditional, but ad hoc, loss function:

$$
\min _{\left\{i_{s}\right\}_{s=t}^{\infty}} \frac{1}{2} \mathcal{E}_{t} \sum_{s=t}^{\infty} \beta^{s-t}\left[\left(\pi_{a s}+\pi_{b s}\right)^{2}+0.5\left(y_{a s}+y_{b s}\right)^{2}\right] .
$$

In other words, the central bank targets union-wide consumer price inflation and output ${ }^{8}$. We take the value of 0.5 for the weight on output variability because this is a conventional value in the literature ${ }^{9}$. As we shall see in Section 2.7 the microfounded social welfare function will include domestic inflation and a more complicated structure of terms concerned with output variability and inflation persistence.

\subsection{Behaviour of the Fiscal Authorities}

In this paper, we postulate that the fiscal authorities are never constrained by any solvency requirements: we only study the role of fiscal policy in stabilisation of the economy. We assume that they adjust disequilibrium government spending so as to target output and inflation (as the monetary authorities do), and that they also target the primary fiscal deficit. This last assumption could reflect either a desire to run a balanced budget, or the impact of a regulatory framework such as the Stability and Growth Pact. We examine implications of this extra component of their loss function at some length below. As a result, the loss functions for the $k$-th authority is:

$$
\min _{\left\{g_{k s}\right\}_{s=t}^{\infty}} \frac{1}{2} \mathcal{E}_{t} \sum_{s=t}^{\infty} \beta^{s-t}\left[\pi_{k s}^{2}+0.5 y_{k s}^{2}+\rho d_{k s}^{2}\right]
$$

where $d_{t}$ denotes the log-deviation of the primary deficit from its level under price flexibility. $d_{t}$ can be found from

$$
\delta_{d} d_{k t}=(1-\theta) g_{k t}-\tau y_{k t}
$$

\footnotetext{
${ }^{8}$ Using consumer price inflation reflects current practice among central banks.

${ }^{9}$ See Aizenman and Frenkel (1985), Horowitz (1987). One reason for choosing the weight on output as 0.5 is that studies suggest that between zero and one the resulting policy frontier is relatively 'square' (see Bean (1998) for the UK, Black, Macklem, and Rose (1998) for Canada and Debelle (1999) for Australia). In this case a policymaker would avoid choosing an extreme number for this weight.
} 
where, as defined above, $1-\theta$ is the share of government consumption in the economy, $\tau$ is wage income tax rate and $\delta_{d}$ is equilibrium level of the real primary deficit ${ }^{10}$. $\rho$ denotes the weight the fiscal authority places on minimising the deviation of the deficit from the equilibrium primary deficit. We use the deviation of the deficit from its level under price flexibility rather than its deviation from the steady state because we believe the former is closer to the Stability and Growth Pact, although nothing important depends on this judgment.

We assume no other constraints on fiscal policy and no lags in its implementation.

\subsection{Social Loss Function}

The three policymakers solve their optimisation problems each period, given initial conditions and time preferences. The resulting optimal policy reactions lead to a stochastic equilibria that should be compared across a suitable metric. The obvious choice of this metric is the microfounded union-wide social loss, which takes the form

$$
\mathcal{L}=\mathcal{E}_{t} \sum_{s=t}^{\infty} \beta^{s-t}\left(\mathcal{U}_{a s}+\mathcal{U}_{b s}\right)=\mathcal{E}_{t} \sum_{s=t}^{\infty} \beta^{s-t} \mathcal{U}_{s}
$$

where the intra-period loss $\mathcal{U}_{s}$ takes the form (see Rotemberg and Woodford (1997), Beetsma and Jensen (2003), Steinsson (2003), and Appendix B to this paper for a discussion of the derivation):

$$
\begin{aligned}
\mathcal{U}_{s} & =\lambda_{c}\left(c_{a s}^{2}+c_{b s}^{2}\right)+\lambda_{y}\left(y_{a s}^{2}+y_{b s}^{2}\right)+\lambda_{g}\left(g_{a s}^{2}+g_{b s}^{2}\right) \\
& +\lambda_{s} s_{a b s}^{2}+\lambda_{s c} s_{a b s} c_{a s}-\lambda_{s c} s_{a b s} c_{b s}+\lambda_{\pi}\left(\pi_{H a s}^{2}+\pi_{H b s}^{2}\right)+\mu_{\Delta \pi}\left(\left(\Delta \pi_{H a s}\right)^{2}+\left(\Delta \pi_{H b s}\right)^{2}\right) \\
& +\nu_{c n} c_{a s}\left[\hat{Y}_{a s}^{n}-\hat{C}_{a}^{n}+\nu_{c s} \hat{S}_{a b s}^{n}\right]+\nu_{c n} c_{b s}\left[\hat{Y}_{b s}^{n}-\hat{C}_{b s}^{n}-\nu_{c s} \hat{S}_{a b s}^{n}\right] \\
& +\nu_{x n} y_{a s}\left[\hat{C}_{a s}^{n}-\hat{Y}_{a s}^{n}+\nu_{x s} \hat{S}_{a b s}^{n}\right]+\nu_{x n} y_{b s}\left[\hat{C}_{b s}^{n}-\hat{Y}_{b s}^{n}-\nu_{x s} \hat{S}_{a b s}^{n}\right] \\
& +\nu_{g n} g_{a s}\left[\hat{Y}_{a s}^{n}-\hat{G}_{a s}^{n}+\nu_{g s} \hat{S}_{a b s}^{n}\right]+\nu_{g n} g_{b s}\left[\hat{Y}_{b s}^{n}-G_{b s}^{n}-\nu_{g s} \hat{S}_{a b s}^{n}\right] \\
& +\nu_{s n} s_{a b s}\left[\nu_{s s} \hat{S}_{a b s}^{n}+\left(\hat{Y}_{a s}^{n}-\hat{Y}_{b s}^{n}\right)-\left(\hat{C}_{a s}^{n}-\hat{C}_{b s}^{n}\right)\right] \\
& +\mu_{y}\left(y_{a s-1}^{2}+y_{b s-1}^{2}\right)+\mu_{y \Delta \pi}\left(y_{a s-1} \Delta \pi_{H a s}+y_{b s-1} \Delta \pi_{H b s}\right)+t i p(3)
\end{aligned}
$$

There are two unconventional features of this loss function. First, terms with $\mu$-coefficients are present only because of rule of thumb price setters. The presence of these terms implies that inflation and output will be brought back to the equilibrium smoothly. Steinsson (2003) has shown that when the private sector is predominantly backward-looking, terms with weights denoted by $\mu$ dominate the loss function, and that conversely, when the private sector is forward-looking these $\mu$-terms essentially disappear. Second, the terms with weights denoted by $\nu$ arise, as Kirsanova, Leith, and Wren-Lewis (2004) discuss in detail, because the economy is open. With taste/technology shocks it is in general no longer optimal to exactly reproduce the flexible price equilibrium, because

\footnotetext{
${ }^{10}$ We assume some positive level of domestic debt in equilibrium, $B$, and if $\theta$ is given, this defines equilibrium $\tau$ and $\delta_{d}$.
} 
changes in the terms of trade alter the impact of the monopoly distortion, and this introduces 'linear in policy' terms with a $\nu$ coefficient.

To interpret the values of the social loss, we can express them in terms of compensating consumption - the permanent fall in the steady state consumption level that would balance the welfare gain from eliminating the volatility of consumption, government spending and leisure (Lucas (1987)). As explained in Appendix $\mathrm{C}$, the percentage change in consumption level, $\Omega$, that is needed to compensate differences in welfare of two regimes with social losses $\mathcal{L}_{1}$ and $\mathcal{L}_{2}$ is given by (27):

$$
\Omega=\sigma\left(1-\sqrt{1+\frac{(1-\beta)}{\sigma} \mathcal{E}_{t} \sum_{s=t}^{\infty} \beta^{s-t}\left(\mathcal{U}_{2 s}-\mathcal{U}_{1 s}\right)}\right)
$$

\subsection{Policy Game}

The focus of this paper is to study non-cooperative game between monetary and fiscal authorities, in which monetary authorities lead. The monetary authorities move first, taking into account the reaction of the two following fiscal authorities and of the private sector in both countries. The fiscal authorities play a Nash game with each other, but they follow the monetary authority and lead the private sector. The private sector is an ultimate follower, and (as is standard in the macroeconomic literature) its optimisation problem is solved out and represented by the two reaction equations, the IS curve and the Phillips curve (18)-(21). All authorities act under discretion, i.e. we solve the model under a time-consistency constraint. This is most appropriate for our purposes, but we believe our results would be robust to alternatives.

The solution of a leadership game with two optimising policymakers and the private sector as an ultimate follower is discussed in Blake and Kirsanova (2003). Here, we extend their analysis, since instead of one follower we have two fiscal authorities, who both follow the monetary authority, and are engaged in a Nash game with each other, and then lead the private sector. The Nash game is studied in detail in the literature on macroeconomic policy coordination, see for example Currie and Levine (1993), and its solution procedure consists essentially of two Oudiz and Sachs (1985) algorithms (one for each fiscal authority) which we need to iterate between ${ }^{11}$. As our framework is linear-quadratic, certainty equivalence applies and the policy reaction functions which emerge from these algorithms do not depend on the size or distribution of shocks.

\section{Calibration}

Because of the microfounded nature of the model, there are relatively few parameters to calibrate, given in Table 1. One period is taken as equal to one quarter of a year. We set the discount factor of the private sector (and policy makers) to $\beta=0.99$.

\footnotetext{
${ }^{11}$ Appendix D gives a more detailed explanation.
} 
Perhaps the most important parameter in our model is the proportion of rule of thumb price setters, $\omega$. Our knowledge regarding inflation persistence is very insecure. All empirical studies are unanimous in concluding that an empirical Phillips curve has a significant backward-looking component. The estimates of the exact weight $\chi$, however, differ widely. Gali and Gertler (1999), Benigno and Lopez-Salido (2002) find a predominantly forward-looking specification of the Phillips curve, while Mehra (2004) finds an extremely backward-looking specification. Mankiw (2001) argues that stylised empirical facts are inconsistent with predominantly forward-looking Phillips Curve. Therefore, we calibrate $\omega=0.5$ for the base-line case specification, which corresponds to a forward-looking coefficient of $\chi=0.3$ in the Phillips curves (20)-(21), but we also look at robustness to alternative values extensively below.

To calibrate parameter $\delta$ we follow Stensson's procedure, which is as follows. The possible range of values for $\omega$ in the Phillips curve is $0 \leq \omega \leq 1$. As noted above, when $\omega \rightarrow 0$ it collapses to the familiar purely forward-looking specification of Woodford (2003) $\pi_{t}=\beta \pi_{t+1}+\kappa_{c} c_{t}+\kappa_{y 0} y_{t}+\kappa_{s} s_{t}$, whilst when $\omega \rightarrow 1$, it collapses to $\pi_{t}=\pi_{t-1}+(1-\gamma) \delta x_{t-1}$, which is the accelerationist Phillips curve. The Stensson's procedure for calibrating $\delta$ assumes that demand pressure in both these extreme cases is equal, i.e. it assumes that $\kappa_{c}+\kappa_{y 0}=(1-\gamma) \delta$. This equation can then be solved to provide a value for $\delta$. With this choice of $\delta$ total demand pressure in our general specification is independent of the number of rule-of-thumb price setters, $\omega$, and is equal to: $\kappa=\kappa_{c}+\kappa_{y 0}+\kappa_{y 1}=(1-\gamma)(1-\gamma \beta) / \sigma \gamma$.

We follow the literature in setting $\gamma=0.75$, which implies that, on average, prices (and wages) last for one year. We assume that each economy consumes $30 \%$ of imported goods. For the parameters related to fiscal policy, we calibrate the ratio of private consumption to output as 75 percent; and we assume that the equilibrium ratio of domestic debt to output is 60 percent. Then the debt accumulation equation gives us the equilibrium level of the primary surplus and the tax rate.

This calibration completely defines the coefficients of the welfare function, which are given in Table 1. It is apparent that the resulting coefficient on output stabilisation in social welfare, $\lambda$, is very small (at around 0.01) compared to the weight traditionally adopted in the monetary policy literature of around ${ }^{12}$ 0.5. In order to evaluate the social loss, which results from the optimal policies which we have designed ${ }^{13}$, we calibrate the standard deviations of shocks hitting the economies as follows. We assume that the standard deviations of cost-push and taste/technology shocks are equal. This is common in the literature, in which a consensus number is $0.5 \%$, see, e.g. Jensen and McCallum (2002), Bean, Nikolov, and Larsen (2002)). All shocks are independent.

\footnotetext{
${ }^{12}$ This larger conventional value for the weight may result from the involuntary unemployment, a phenomenon not addressed in our model.

${ }^{13}$ Our optimal policy is certainty-equivalent: independent of stochastic distributions of shocks.
} 


\section{Results}

\subsection{Impulse Responses to Shocks}

The solution of this model is a set of optimal reaction functions for the monetary and fiscal authorities, given the model structure and the assumption that each country is subject to cost-push and taste/technology shocks. We display the responses of the economy under these rules to both symmetric and asymmetric shocks. We have checked, by examining eigenvalues, that all our solutions are saddle-path stable.

Figure 1 shows the responses of the economy to cost-push shocks, either symmetric, or asymmetric. The figure shows the responses for three cases: with stabilising fiscal policy (solid line), with no change in fiscal policy (dashed line) and with constant fiscal deficits (dotted line). Outcomes with no fiscal policy change are obtained simply by removing fiscal authorities from the game (so that government spending is kept constant) and calculating outcomes when only monetary policy is active. Outcomes with constant deficits are obtained by introducing fiscal authorities into the game, but placing a very large weight $\rho \gg 1$ on the volatility of deficits in the fiscal objectives (26). Stabilising fiscal policy similarly corresponds to a small value for $\rho \ll 1$.

The left hand panel of Figure 1 shows that the model produces similar responses of inflation and output to symmetric shocks in all three cases, that is whether there is stabilising fiscal policy, or no fiscal policy change, or there are constant fiscal deficits. Monetary policy can deal effectively with symmetric shocks, and adding fiscal stabilisation to monetary policy produces only small improvements in the response of inflation, and only small changes in the behaviour of output. But the differences in other trajectories when fiscal policy is active are revealing. The inflation shock produces a large fiscal expansion, which in turn leads to a much larger interest rate increase, so as to discipline the inflation outcomes, which would result from this fiscal expansion. The combination of a contractionary monetary policy and expansionary fiscal policy in response to a cost-push shock arises because inflation is more sensitive to consumption than to output. As a result, a tough monetary policy will reduce inflation through lower consumption, but the impact on output can be partly compensated for by higher government spending. In addition, movements in the fiscal and monetary policy instruments affect aggregate demand in different ways: a fiscal expansion increases aggregate demand now, whereas an interest rate increase changes the pattern of demand by delaying consumption.

The right hand panel of Figure 1 reports the response with asymmetric shocks. Such shocks cannot be dealt with at all by monetary policy and Figure 1 confirms this: they produce a zero response in interest rates. Without any fiscal stabilisation at all the economy experiences significant oscillations. The reason for this is our assumption of inflation inertia which, in a monetary union, is an important source of potential instability. Suppose for some reason that output in one country 
is higher than in another. Inflation in that country will then rise gradually (because of inertia), and the real interest rate will continue to fall, for some period of time. This falling real interest rate would cause further output gains, which might be so large as to lead to actual instability of the economy. Even if instability is avoided, the adjustment mechanism is slow and cyclical. This is because the price level tends to overshoot. The initial rise in demand will cause inflation, and the level of prices will rise, eventually enough to cause low demand and disinflation. But when the price level and demand have returned to zero prices are still falling. This will lead to high demand in the future, which will cause a return of inflation, leading to higher prices again and so $\mathrm{on}^{14}$. This is very different from what would happen if inflation was entirely forward-looking. In that case inflation would jump up in response to the higher demand and then gradually fall, so that the real interest rate would be higher, helping to bring the economy back to the equilibrium.

Figure 1 shows that active fiscal policy is able to stabilise the economy in the face of such asymmetric shocks. Without an active fiscal policy the economy cycles. With no fiscal policy change, an increase in inflation causes such a large output fall that inflation then overshoots downwards, and the resulting fall in the price level makes output overshoot upwards again, in the way discussed above. Active fiscal policy makes output recover much faster after its initial fall and prevents the downward overshoot of prices. We shall see that such active fiscal policy will increase welfare.

What is the analytical reason that fiscal policy can make such a difference to the control of these asymmetric cost-push shocks? In a monetary union, because of the fixed exchange rate, the relative price level between the two countries must return to its initial position following a temporary asymmetric shock. This stabilisation of the price-level is costly because the integral of relative inflation, rather than its level, has to come to zero following a shock. In effect the monetary union is forcing the economy to operate like it would with price level targeting; inflationary bygones cannot be bygones. Fiscal policy can help to prevent excessive costs of this. It cannot circumvent the constraint - but it prevents overshooting in response to it $^{15}$.

\subsection{Welfare Outcomes}

Overall Figure 1 suggests that there might be a substantial gain in welfare from fiscal stabilisation against asymmetric shocks, since volatility obviously falls. We now explore the size of the gain. We hit the economy with both cost-push and taste shocks: as we noted above taste shocks on their own would have no effect on welfare, but they do influence the size of the impact of the cost push shocks. However, our results would be virtually identical if we hit the economy with only cost-push shocks.

\footnotetext{
${ }^{14}$ For detailed dynamic analysis of instability mechanisms in a monetary union when inflation is persistent, see Kirsanova, Vines, and Wren-Lewis (2004).

${ }^{15}$ In the language of Phillips (1954), fiscal policy provides 'derivative control' which greatly improves the behaviour of the system as it returns to equilibrium.
} 
The upper panel of Figure 2 shows how the social gain varies as we vary the level of fiscal activity i.e. as we vary the weight $\rho$ on the volatility of deficits in the fiscal objectives (26). We plot the level of social gain for a particular value of $\rho$ against a measure of the level of fiscal activity for that value of $\rho$. The measure we choose is the the standard deviation of the fiscal deficit measured as a percentage of GDP, $\operatorname{sd}(d) / Y$. Values of the social gain are plotted as a percentage of steady state consumption. The benchmark case is the case when fiscal policy instruments are constant (dashed line). The case of constant fiscal deficits is shown as point $A$, and starting from this point, along the solid line fiscal policy becomes increasingly active. We also plot the case where there are no shocks (dotted line) and the case of cooperation of all three authorities in pursuit of common social objectives (dash-dotted line).

It is apparent that the policy of constant government spending delivers very similar outcomes to the case with constant fiscal deficits in the case of symmetric shocks, and actually does worse when there are asymmetric shocks. This is not surprising; automatic stabilisers are unlikely to be helpful with Ricardian consumers.

The gain from active fiscal stabilisation against asymmetric cost-push shocks is substantial: a level of fiscal activity that produces a standard deviation of $0.9 \%$ for the fiscal deficit corresponds to a gain in consumption of around $0.94 \%$. The gain from fiscal stabilisation against symmetric shocks is a lot smaller, $0.31 \%$ of consumption.

The highest line indicates the consumption gain if shocks in the economy could be entirely avoided, relative to the case with automatic stabilisers and shocks. Thus active fiscal policy delivers more than $30 \%$ of the gain which would happen if there were no shocks in the case of asymmetric shocks and $22 \%$ of this in the case of symmetric shocks (after the monetary policy have eliminated some of them of course).

For both symmetric and asymmetric shocks, there is a substantial gap between the maximum gain that consumers can achieve if the autorities non-cooperatively maximise realistic but ad hoc objectives as we suppose, and the gain that consumers could obtain if the authorities cooperate in maximising social welfare. This is due to two factors: the absence of cooperation and the difference between the objectives of the authorities and social welfare. Experiments with varying the coefficient on demand pressure in the Phillips curve $\kappa$ (which also changes the weight on output stabilisation in the social objective relative to the weight on inflation stabilisation), suggest that this gap is mostly explained by the differences in objectives. We discuss this issue in the next section $^{16}$.

The lower panel of Figure 2 shows the breakdown of the loss as the level of fiscal activity

\footnotetext{
${ }^{16}$ It is problematic to try to solve for a non-cooperative outcome where each player uses social objectives. Social welfare metrics for an individual open economy and for a monetary union as a whole are different. When deriving either of them, we would have to make an assumption about who chooses employment subsidies (national governments or union authorities). Whatever choice we make, one or the other metric would contain linear terms, that implies a departure from the linear-quadratic framework.
} 
varies. The two pictures in this panel show, for each level of fiscal activity, the social loss that is due to its main components: inflation, the change in inflation, government consumption, and the rest (output, consumption, term of trade and their cross-terms). The picture on the left looks at symmetric shocks, and the right panel looks at asymmetric shocks. It is apparent that in the case of symmetric shocks, as fiscal policy becomes more active, increasing costs of fiscal volatility are substituted fora reduction in costs arising from the volatility of inflation. In the case of asymmetric shocks, the composition of costs remains more stable. Comparison of both pictures, where the standard deviations of the shocks are the same, suggests that the majority of losses are from asymmetric shocks, even if active fiscal policy removes a large part of them.

We now explore how these results vary as we change the parameters of the system. We focus on asymmetric shocks as fiscal policy is most important in this case.

\subsection{Sensitivity of the Results: the Importance of Persistence and Lags}

The improvement in responses to asymmetric shocks, and so the improvement in welfare, brought about by active fiscal policy, depends crucially on one key parameter in the model: the proportion of rule of thumb price setters $\omega$. In Section 3 we argued that our knowledge about this parameter is very insecure. We now discuss the implications of changes in this parameter for our results. We also consider the implications of longer lags between demand and inflation.

Table 2 shows the welfare changes for different fiscal regimes and parameterisations of the model in terms of the equivalent gain or loss in consumption measured as a percentage of GDP. Column (1) shows the change in steady state consumption, which is equivalent to the change in welfare, in moving from no-change policy to a policy of constant deficits. Column (2) shows the gain from moving from a policy of using automatic stabilisers to a policy regime in which fiscal policy is active. In column (3), we show the consumption gain that would be obtained if there were no macroeconomic volatility (i.e. if there were no shocks), again relative to the no-change case. Comparing column (2) to column (3) then shows the proportion of the total costs of macroeconomic volatility, caused by asymmetric shocks, that can be eliminated by using active fiscal policy.

The first row shows the base-line case described above. The second and third rows of Table 2 show that when the proportion of forward-looking individuals, $1-\omega$, is large, the potential gains from fiscal stabilisation are small. As we would expect, the large fraction of forward-looking price-setters implies that relative prices in the countries of the union adjust quickly, and hence asymmetric shocks die out quickly, without any policy intervention (seeDuarte and Wolman (2002) and Smets and Wouters (2003) for example). However, we might still expect some fiscal policy reaction to dampen the impact of the cost-push shock. Its almost complete absence here can be entirely explained by the relatively small weight on output in the Phillips curve. In equation (20), when all firms are forward looking the parameter $\kappa_{y 0}$ is of the order of 0.01 , while the parameter $\kappa_{c}$ 
is four times larger. After allowing for interrelationships between consumption and the exchange rate, the coefficient on the policy instrument $g$ is around 0.003. Very large changes in government spending (and output) would therefore be required to counteract the impact of a cost-push shock. As long as government spending and output have some weight in the welfare function, optimal fiscal policy will do very little to offset cost-push shocks when inflation is completely forward looking. ${ }^{17}$

The fourth row of the Table investigates the sensitivity of our results to the size of the demand pressure terms in the Phillips curve. When coefficient $\kappa$ is increased ${ }^{18}$, the welfare gain from fiscal stabilisation remains substantial. In this case the gap between the gain that consumers can achieve if the autorities non-cooperatively maximise realistic but ad hoc objectives, and the gain that consumers obtain if the authorities cooperate on maximising social welfare is $0.2 \%$ of the steady state consumption, compared to $1.12 \%$ for the baseline case. This suggests that the loss from non-cooperation is of lower order than the loss due to differing objectives.

The fifth row of the table shows the results for the base-line level of the proportion of backwardlooking price setters but with a lengthened lag structure on the demand terms in the Phillips curve. The motivation for this experiment was to see if any additional lags introduced in the specification of the inflation equation might alter the stabilisation properties of fiscal policy ${ }^{19}$. The effect of this is to redistribute the lagged output terms in the Phillips curve (due to backward-looking pricesetters) from all being at a lag of one quarter to half being at a lag of one quarter and half at a lag of two quarters ${ }^{20}$. Empirically, this is plausible and seemingly small change. It causes fiscal policy to have a much larger welfare impact. In this case, the welfare gain from fiscal stabilisation is substantially higher than in any other cases shown, and active fiscal policy is able to remove effects of around $50 \%$ of all shocks ${ }^{21}$. Without fiscal policy, the lengthening of the lag structure causes the economy to have a very prolonged cyclical response to asymmetric shocks. When the system is close to being unstable without fiscal policy, the fiscal stabilisation then produces very large welfare gains ${ }^{22}$.

\footnotetext{
${ }^{17}$ If welfare is given by $\pi^{2}+a y^{2}$, and inflation by $\pi=c y+\eta$, then if $y$ is an instrument and $\eta=1$, the loss under the optimal policy will be $a /\left(a+c^{2}\right)$, compared to 1 under no control. Thus if $c$ is small, the gain in welfare from choosing optimal $y$ will be very small.

18 To examine this case we calibrated $\kappa=.25$ first, given $\omega$, and then derived corresponding $\delta$. This resulting $\delta$ affects coefficients of the social loss function, so the sum of $\lambda$-coefficients there also increase substantially and becomes close to 0.16 , compared to 0.06 in the original calibration.

${ }^{19}$ Frequently in the literature, when the Phillips curve is calibrated to be predominantly forward-looking, in order to achieve realistic hump-shaped impulse responses in simulations, researchers use autocorrelated shocks, that is equivalent to including arbitrary lags in the model (Smets and Wouters (2002), for example). Bean (1998) argues that it takes a year for demand to affect inflation.

${ }^{20}$ Basically, instead of term $\ldots \kappa_{y 1} y_{t-1}$ in the Phillips curve we have $\ldots \kappa_{y 1}^{*} y_{t-1}+\kappa_{y 2}^{*} y_{t-2}$, with $\kappa_{y 1}^{*}+\kappa_{y 2}^{*}=\kappa_{y 1}$. The welfare measure takes into account the new specification, see Additional Appendix. (The numerical experiment here assumes $\kappa_{y 1}^{*}=\kappa_{y 2}^{*}=\kappa_{y 1} / 2$ )

${ }^{21}$ This figure becomes $70 \%$ if we also set $\kappa=0.25$.

${ }^{22}$ The ability of lags to cause a system to become more and more volatile has a long history in economic literature (Phillips (1957)). For an exposition of the use of control methods to derive PID control in economic systems see Vines, Maceijowsky, and Meade (1983).
} 


\section{Conclusion}

This paper shows that the active use of fiscal policy in a monetary union can result in a significant increase in welfare. This welfare gain is mainly brought about by the ability of the fiscal policy to mitigate the effects of asymmetric shocks cost-push shocks.

We find that the importance of fiscal policy for stabilising asymmetric shocks depends to a large extent on the structure of the Phillips curve. When there is persistence in inflation, outcomes with fiscal stabilisation produce significantly lower social losses than a fiscal policy with constant deficits or one with constant government spending. We also find that fiscal stabilisation is more important when there are lags in the effect of demand in the Phillips curve.

We have examined fiscal policy that is the outcome of optimisation by the fiscal authorities, rather than studying fiscal feedback rules. Our setup is a suitable one to explain the behaviour of fiscal authorities who are given an objective, such as helping with stabilisation without exceeding certain deficit bounds, like that contained in the Stabilisty and Growth Pact. An alternative approach would be to supply fiscal authorities with a (state-contingent) rule. This could either be one with given coefficients, or the authorities could be required to choose the coefficients so as to maximise a social objective function. All of these approaches assume different institutional structures, and it would be interesting to compare their relative merits. In particular, the use of specified rules could help capture any institutional lags or rigidities that were thought to characterise the operation of fiscal policy.

Finally, this research does not take into account many of the reasons why restrictions on fiscal policy might be desirable. For instance we do not take into account the possibility of fiscal insolvency, or the political economy factors which might lead to 'excess deficits'. If fiscal policy had small welfare advantages in terms of macroeconomic stabilisation, then one could argue for tight fiscal restrictions to address these problems. However, we have found that fiscal policy can play a very important role in macroeconomic stabilisation in a monetary union. We therefore argue that any regulatory framework for fiscal policy should allow it to play a substantial role in stabilising the economy. 


\begin{tabular}{lcc}
\hline \hline Key Parameters & Mnemonics & Value \\
\hline \hline Discount factor & $\beta$ & 0.99 \\
Share of rule-of-thumb price-setters & $\omega$ & 0.5 \\
Proportion of agents who able to reset their price within a period & $1-\gamma$ & 0.25 \\
Share of the government sector in the economy & $1-\theta$ & 0.75 \\
Steady state ratio of domestic debt to output & $B / Y$ & 0.6 \\
Intertemporal substitution rate & $\sigma$ & 0.5 \\
Elasticity of substitution between domestic and foreign goods & $\eta$ & 0.3 \\
Average elasticity of substitution between domestic goods & $\epsilon$ & 5.0 \\
Production risk aversion & $1 / \psi$ & 0.5 \\
Share of domestic goods in consumption basket & $\alpha_{d}$ & 0.7 \\
\hline \hline Implied Parameters in system (18)-(24) & Mnemonics & Value \\
\hline \hline Tax Rate & $\tau$ & 0.256 \\
Steady state ratio of primary real surplus to output & $\delta_{d}$ & 0.006 \\
Total weight on demand pressure in the Phillips curve & $\kappa$ & 0.061 \\
Weight on forward inflation in the Phillips curve & $\chi$ & 0.3 \\
Weight on the country's term of trade in AD & $2 \theta \eta \alpha_{d} \alpha_{n}$ & 0.09 \\
\hline \hline Implied Parameters in the Social Loss Function $(27)$ & Mnemonics & Value \\
\hline \hline Consumption variability & $\lambda_{c}$ & 0.007 \\
Output variability & $\lambda_{y}+\mu_{y 1}$ & 0.007 \\
Variability of government consumption & $\lambda_{g}$ & 0.002 \\
Variability of inflation growth rate & $\mu_{\Delta \pi}$ & 1.33 \\
Covariance of the first lag in output and inflation growth rate & $\mu_{y 1 \Delta \pi}$ & 0.16 \\
Sum of demand-variability related terms & $\lambda$ & 0.017 \\
\hline \hline
\end{tabular}

Table 1: Parameter values

\begin{tabular}{ccc|ccc}
\hline \hline $\begin{array}{c}\text { Key parameter } \\
\text { values }\end{array}$ & \multicolumn{2}{c|}{ Implied } & Constant deficit & Active fiscal policy & No shocks \\
$\%$ & & $\%$ & $(2)$ & $(3)$ \\
\hline & & & $(1)$ & 0.94 & 3.12 \\
\hline$=0.5$ & 0.3 & 0.06 & 0.18 & 0.03 & 0.91 \\
$\omega=0.3$ & 0.5 & 0.06 & 0.03 & 0.004 & 0.34 \\
$\omega=0.15$ & 0.7 & 0.06 & 0.004 & 1.13 & 2.25 \\
\hline$\omega=0.5^{*}$ & 0.3 & 0.25 & 0.14 & 1.42 & 3.70 \\
\hline $\begin{array}{c}\omega=0.5 \text { and } \\
\text { demand lags }\end{array}$ & 0.3 & 0.06 & 0.06 & & \\
\hline \hline
\end{tabular}

*- This is different from the first row, as we use the different way of deriving $\kappa$, as clarified in Footnote 18

Table 2: Welfare relative to that with Constant Government Spending: Consumption gains. Asymmetric shocks 

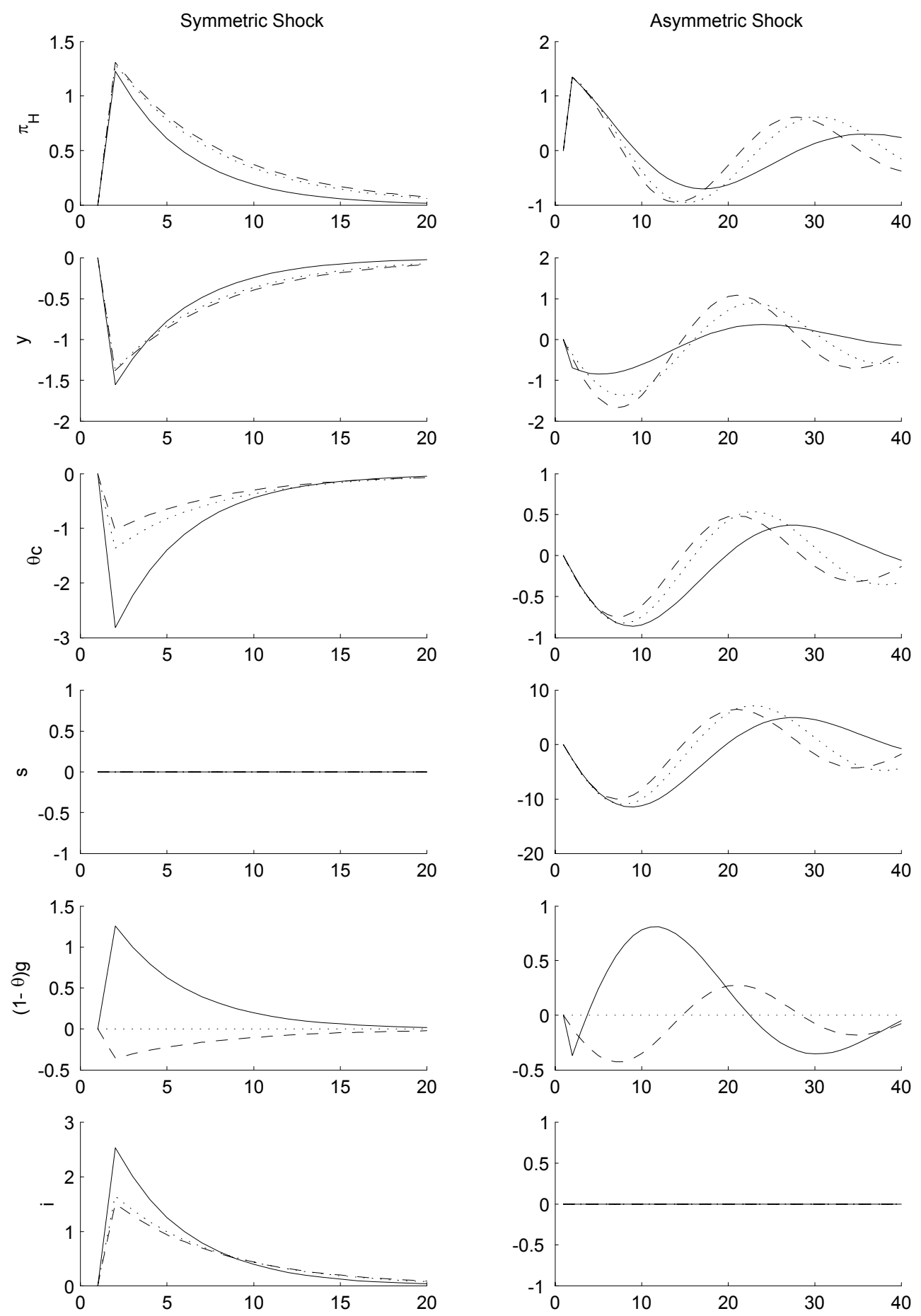

Figure 1: Response to cost-push shocks. Solid line denotes optimal policy, dashed line denotes policy when the budget is close to balanced every period, and dotted line denotes policy with constant government spendings. 

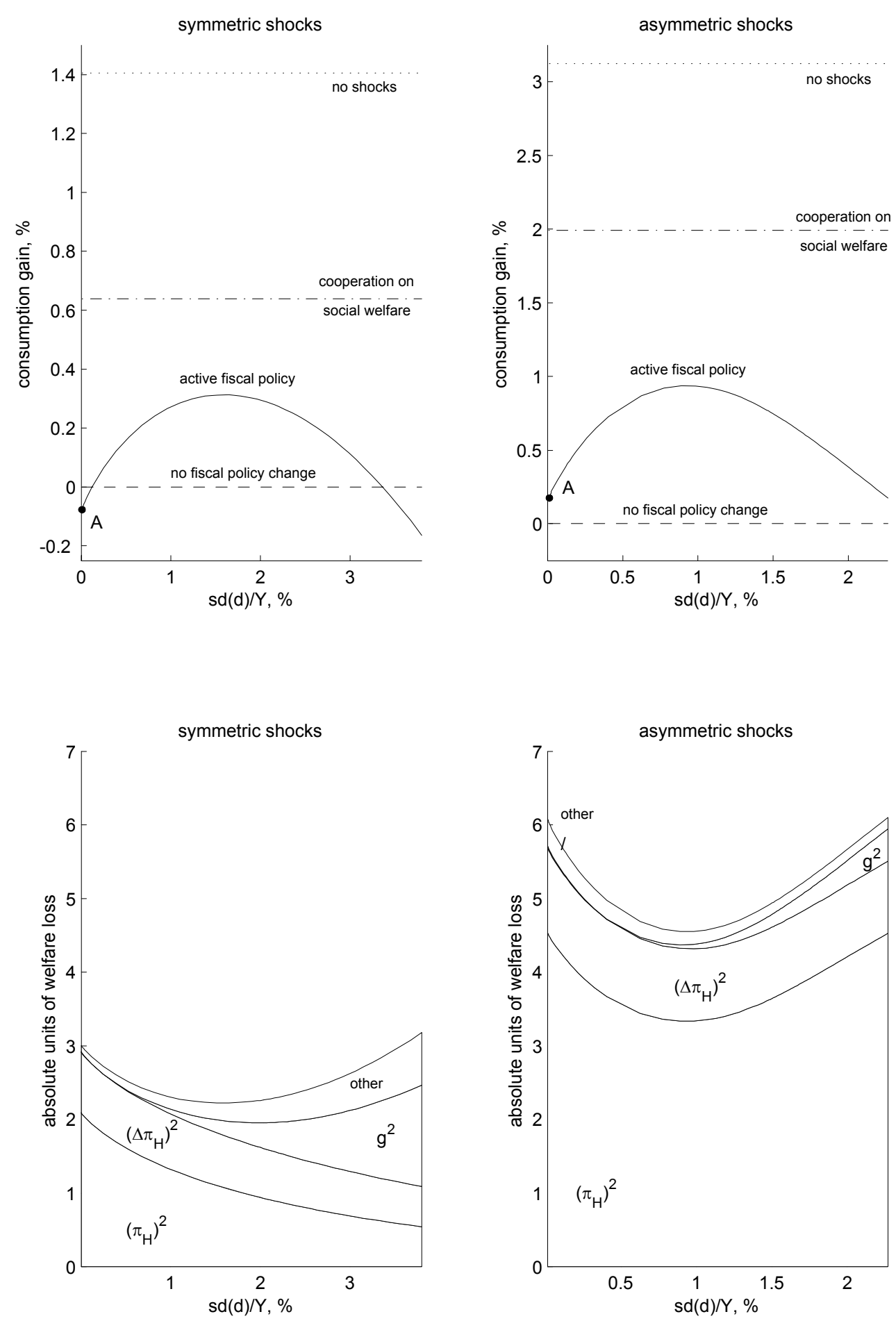

Figure 2: Social loss as function of fiscal activity. 


\section{References}

Aizenman, J., And J. A. Frenkel (1985): "Optimal Wage Indexation, Foreign Exchange Intervention, and Monetary Policy," The American Economic Review, 75(3), 402-423.

BEAN, C. (1998): "The new UK monetary arrangements: a view from the literature," Economic Journal, 108, 1795-1809.

Bean, C., K. Nikolov, and J. Larsen (2002): "Financial frictions and the monetary transmission mechanism: theory, evidence and policy implications," Working paper no. 113, European Central Bank.

Beetsma, R., and H. Jensen (2003): "Mark-up Fluctuations and Fiscal Policy Stabilization in a Monetary Union," mimeo, Universities of Amsterdam and Copenhagen.

Beetsma, R. M. W. J., and H. Jensen (2004): "Monetary and Fiscal Policy Interactions in a Micro-founded Model of a Monetary Union," Mimeo, Universities of Amsterdam and Copenhagen.

Benigno, G., and P. Benigno (2000): "Monetary Policy Rules and the Exchange Rate," Discussion paper, Technical Appendix to CEPR Discussion Paper No. 2807.

Benigno, P., and J. D. Lopez-Salido (2002): "Inflation persistence and optimal monetary policy in the euro area," .

Benigno, P., and M. Woodford (2003): "Optimal Monetary and Fiscal Policy: A LinearQuadratic Approach," mimeo, Princeton University.

(2004): "Inflation Stabilization and Welfare: The Case of a Distorted Steady State," mimeo, Princeton University.

Black, R., T. Macklem, and D. Rose (1998): "On Policy Rules for Price Stability," in Price Stability, Inflation Targets and Monetary Policy. Ottawa: Bank of Canada, Proceedings of a conference held by the Bank of Canada, May 1997.

Blake, A., and T. Kirsanova (2003): "Non-cooperative Monetary and Fiscal Policy: The Value of Leadership," mimeo, University of Exeter.

Blanchard, O., and C. Kahn (1980): "The Solution of Linear Difference Models Under Rational Expectations," Econometrica, 48, 1305-1311.

Calmfors, L. (2003): "Fiscal Policy to Stabilise the Domestic Economy in the EMU: What Can We Learn from Monetary Policy?," CESifo Economic Studies, 49(3), 319-353.

Currie, D., And P. Levine (1993): Rules, Reputation and Macroeconomic Policy Coordination. Cambridge University Press, Cambridge.

Debelle, G. (1999): "Inflation Targeting and Output Stabilisation," Reserve Bank of Australia Research Discussion Paper No. 1999-08.

Dixit, A., And J. Stiglitz (1977): "Monopolistic Competition and Optimum product Diversity," American Economic Review, 67, 297-308. 
Duarte, M., and A. Wolman (2002): "Regional Inflation in a Currency Union: Fiscal Policy vs. Fundamentals," ECB.

Gali, J., And M. Gertler (1999): "Inflation Dynamics: A Structural Econometric Analysis," Journal of Monetary Economics, 44, 195-222.

Gali, J., and T. Monacelli (2002): "Monetary Policy and Exchange Rate Volatility in a Small Open Economy," Working Paper 8905, NBER.

(2004): "Optimal Fiscal Policy in a Monetary Union," .

Horowitz, A. R. (1987): "Loss functions and public policy," Journal of Macroeconomics, 9(4), $789-504$.

Jensen, C., And B. McCallum (2002): "The Non-Optimality of Proposed Monetary Policy Rules Under Timeless Perspective Commitment," Economics Letters, 77, 163-168.

Kirsanova, T., C. Leith, and S. Wren-Lewis (2004): "Should the Exchange Rate be in the Monetary Policy Objective Function?," .

Kirsanova, T., M. Satchi, D. Vines, and S. Wren-Lewis (2004): "Inflation Persistence, Fiscal Constraints and Non-cooperative Authorities: Stabilisation Policy in a Monetary Union," University of Exeter Working Paper, available at www.ex.ac.uk/ tkirsano/asymshockWP.pdf.

Kirsanova, T., D. Vines, and S. Wren-Lewis (2004): "Fiscal Policy and Macroeconomic Stability within a Currency Union," Universities of Exeter and Oxford.

Lane, P. R. (2001): "The New Open Economy Macroeconomics: A Survey," Journal of International Economics, 54.

LuCAs, R. (1987): Models of Business Cycles. Basil Blackwell.

Mankiw, N. (2001): "The Inexorable and Mysterious Tradeoff between Inflation and Unemployment," The Economic Journal, 111, C45-C61.

Menra, Y. P. (2004): "The Output Gap, Expected Future Inflation and Inflation Dynamics: Another Look," Topics in Macroeconomics, 4(1).

Oudiz, G., And J. SAchs (1985): "International Policy Coordination in Dynamic Macroeconomic Models," in International Economic Policy Coordination, ed. by W. H. Buiter, and R. C. Marston. Cambridge University Press, Cambridge.

Phillips, A. W. H. (1954): "Stabilization Policy in a Closed Economy," Economic Journal, 64, 290-323.

(1957): "Stabilization Policy and the Time-Forms of Lagged Responses," Economic Journal, 67, 265-277.

Rotemberg, J. J., And M. Woodford (1997): "An Optimization-based Econometric Framework for the Evaluation of Monetary Policy," in NBER Macroeconomics Annual, pp. 297-344.

Schmitt-Grohe, S., and M. Uribe (2003): "Optimal Simple and Implementable Monetary and Fiscal Rules," mimeo, Duke University. 
Smets, F., and R. Wouters (2002): "Openness, Imperfect Exchange Rate Pass-Through and Monetary Policy," Journal of Monetary Economics, 49.

(2003): "An Estimated Dynamic Stochastic General Equilibrium Model of the Euro Area," Journal of the European Economic Association, 1.

SöDerlind, P. (1999): "Solution and Estimation of RE Macromodels with Optimal Policy," European Economic Review, 43, 813-823.

Steinsson, J. (2003): "Optimal Monetary Policy in an Economy with Inflation Presistence," Journal of Monetary Economics, 50, 1425-1456.

Sutherland, A. (2002): "A Simple Second-Order Solution Method For Dynamic General Equilibrium Models," CEPR discussion paper 3554.

Swedish Committee (2002): "Stabilisation Policy in the monetary union - summary of the report," Discussion paper, Swedish Committee on stabilisation policy for full employment if Sweden joins the Monetary Union.

Treasury (2003): "Submissions on EMU from leading academics," Discussion paper, HM Treasury.

Vines, D., J. Maceijowsky, and J. Meade (1983): Demand Management. Allen \& Unwin, London.

Woodford, M. (2003): Interest and Prices: Foundations of a Theory of Monetary Policy. Princeton University Press, Princeton, NJ. 


\section{A Dynamic System}

\section{A.1 Price-setting decisions}

Pricing behaviour is modelled as in Rotemberg and Woodford (1997) and Steinsson (2003). Households are able to reset their price in each period with probability $1-\gamma$ in which case they re-contract a new price $P_{H}^{F}$. For the rest of the sector the price will rise at the steady state rate of domestic inflation $\bar{\Pi}_{H}$ with probability $\gamma, P_{H k t}=\bar{\Pi}_{H k} P_{H k t-1}$.

Those who recontract a new price (with probability $1-\gamma$ ), are split into backward-looking individuals and forward-looking individuals, in proportion $\omega$, such that the aggregate index of prices set by them is

$$
P_{H k t}^{r}=\left(P_{H k t}^{F}\right)^{1-\omega}\left(P_{H k t}^{B}\right)^{\omega}
$$

Backward-looking individuals set their prices according to the rule of thumb:

$$
P_{H k t}^{B}=P_{H k t-1}^{r} \Pi_{H k t-1}\left(\frac{Y_{k t-1}}{Y_{k t-1}^{n}}\right)^{\delta}
$$

where $\Pi_{H k t}=\frac{P_{H k t}}{P_{H k t-1}}$ and $Y_{k t}^{n}$ is the flexible-price equilibrium level of output.

We define log deviations from the steady state domestic price levels for both types of pricesetters as:

$$
\hat{P}_{H k t}^{B}=\ln \frac{P_{H k t}^{\bar{k}}}{P_{H k t}}, \hat{P}_{H k t}^{F}=\ln \frac{P_{H k t}^{F}}{P_{H k t}}
$$

Production possibilities are specified as follows:

$$
y_{k t}(z)=h_{k t}(z)
$$

The cost of supplying a good is given as $\operatorname{Cost}(z)=\frac{1}{\mu^{w}} w_{k s}(z) h_{k s}(z)=\frac{1}{\mu^{w}} w_{k s}(z) y_{k s}(z)$, where $\mu^{w}$ is a labour subsidy. We do not assume any other taxes and labour is the only cost to the firm.

Each producer understands that sales depend on demand, which is a function of price. Intratemporal consumption optimisation implies

$$
y_{k s}(z)=\left(\frac{p_{H k}(z)}{P_{H k}}\right)^{-\epsilon_{t}} Y_{k} .
$$

so with price flexibility a producer that wishes to maximise profit (in square brackets below) will choose a price at $t$ that maximises

$$
\max _{p_{H k t}(z)} \mathcal{E}_{t} \sum_{s=t}^{\infty} \gamma^{s-t} R_{t, s}\left[p_{H k t}(z) y_{k s}(z)-\frac{1}{\mu^{w}} w_{k s}(z) y_{k s}(z)\right]
$$

This implies the following first order condition:

$$
0=\mathcal{E}_{t} \sum_{s=t}^{\infty} \gamma^{s-t} p_{H k t}^{-\epsilon_{s}-1}(z) R_{t, s} Y_{k s} P_{H k s}^{\epsilon_{s}}\left[p_{H k t}(z)+\frac{\epsilon_{k s}}{\left(1-\epsilon_{k s}\right)} \frac{1}{\mu^{w}} w_{k s}(z)\right]
$$

where $\mu_{k s}=-\frac{\epsilon_{k s}}{1-\epsilon_{k s}}$. This condition holds for both flexible and fixed price equilibria. However, for the fixed price equilibrium, the wage rate is a function of price, set at the period $t$. Substituting for the wage rate, we get a final equation for the optimal $p_{H k t}(z)=p_{H k t}^{F}(z)$

$$
0=\mathcal{E}_{t} \sum_{s=t}^{\infty} \gamma^{s-t} p_{H k t}^{-\epsilon_{s}-1}(z) R_{t, s} Y_{k s}\left(\frac{p_{H k t}(z)}{P_{H k s}}\right)^{-\epsilon_{s}}\left[p_{H K t}(z)-\frac{\mu_{k s}}{\mu^{w}} P_{k s} \frac{v_{y}\left(\left(\frac{p_{H k t}(z)}{P_{H k s}}\right)^{-\epsilon_{s}} Y_{k s}, \xi_{k s}\right)}{(1-\tau) u_{C}\left(C_{k s}^{i}, \xi_{k s}\right)}\right]
$$


where $\tau$ is constant wage income tax. The linearisation of this equation can be found in Rotemberg and Woodford (1997) for the closed economy case. We briefly repeat it here for the open economy.

First of all, the term in the square brackets vanishes in equilibrium so its deviations from the equilibrium are of first order. Therefore, all products of it with terms in front of it will be higher than of first order, unless the first term is taken at its equilibrium level, which is $(\gamma \beta)^{s-t}$, up to some constant multiplier.

Linearising the term in square brackets yields:

$$
\begin{aligned}
& (1-\tau) p_{H k t}(z)-\frac{\mu_{k s}}{\mu^{w}} P_{k s} \frac{v_{y}\left(\left(\frac{p_{H k t}(z)}{P_{H k s}}\right)^{-\epsilon} Y_{k s}, \xi_{k s}\right)}{u_{C}\left(C_{k s}, \xi_{k s}\right)} \\
& =(1-\tau)\left(\hat{p}_{H k t}(z)-\hat{P}_{H k s}+\frac{\epsilon}{\psi}\left(\hat{p}_{H k t}^{f}(z)-\hat{P}_{H k s}\right)-\alpha_{n} \hat{S}_{k \bar{k} s}-\frac{1}{\psi} \hat{Y}_{k s}-\frac{1}{\sigma} \hat{C}_{k s}\right. \\
& \left.-\left(\frac{v_{y \xi}}{v_{y}}-\frac{u_{C \xi}}{u_{C}}\right) \hat{\xi}_{k s}-\hat{\mu}_{k s}\right)
\end{aligned}
$$

where $\hat{S}_{k \bar{k}}=\frac{P_{H \bar{k}}}{P_{H k}}$ is the term of trade and $\sigma=-u_{C} / u_{C C} C, \psi=v_{y} / v_{y y} Y$. We also substituted $\frac{v_{y}}{u_{C}} \frac{\mu}{\mu^{w}}=(1-\tau)$ in all coefficients.

We solve out this equation for prices and, using the fact that $\sum_{s=t}^{\infty}(\gamma \beta)^{s-t} \sum_{m=1}^{s-t} \pi_{H k t+m}=$ $\frac{1}{1-\gamma \beta} \sum_{m=1}^{\infty}(\gamma \beta)^{m} \pi_{H k t+m}$ we obtain the following formula for the forward-looking individuals:

$$
\begin{aligned}
\hat{p}_{H k t}^{F} & =\sum_{m=1}^{\infty}(\gamma \beta)^{k} \pi_{H k t+m}+\frac{(1-\gamma \beta)}{1+\frac{\epsilon}{\psi}} \sum_{s=t}^{\infty}(\gamma \beta)^{s-t}\left[\alpha_{n} \hat{S}_{k \bar{k} s}\right. \\
& \left.+\frac{1}{\psi} \hat{Y}_{k s}+\frac{1}{\sigma} \hat{C}_{k s}+\left(\frac{v_{y \xi}}{v_{y}}-\frac{u_{C C}}{u_{C}}\right) \hat{\xi}_{k s}+\hat{\eta}_{k s}\right]
\end{aligned}
$$

Here $\alpha_{n} \hat{S}_{k \bar{k}}$ comes in as the result of the wedge between consumption of the CPI basket and the production of domestic goods and different prices set on them. The constant tax rate, $\tau$, does not enter the final formula when written in log-deviations from equilibrium (see Benigno and Benigno (2000) for a similar derivation).

This can be rewritten in a quasi-differenced form as:

$$
\begin{aligned}
\hat{P}_{H k t}^{F} & =\gamma \beta \hat{P}_{H k t+1}^{F}+\gamma \beta \pi_{H k t+1} \\
& +\frac{1-\gamma \beta}{1+\frac{\epsilon}{\psi}}\left(\alpha_{n} \hat{S}_{k \bar{k} t}+\frac{1}{\psi} \hat{Y}_{k t}+\frac{1}{\sigma} \hat{C}_{k t}+\left(\frac{v_{y \xi}}{v_{y}}-\frac{u_{C C}}{u_{C}}\right) \hat{\xi}_{k t}+\hat{\eta}_{k t}\right)
\end{aligned}
$$

This formula is not the final Phillips curve, but Steinsson (2003) shows how it can be used to derive the final specification of the Phillips Curve, where we have rule-of-thumb price-setters. Our derivation is identical to his, so will not be repeated here. Formula (32) demonstrates how mark-up shocks enter the Phillips curve. It also demonstrates that the constant wage income tax $\tau$ has no effect on the dynamic equations for log-deviations from the flexible price equilibrium (although it alters the equilibrium choice between consumption and leisure for the consumer).

Finally, the Phillips curve can be written as

$$
\pi_{H k t}=\chi \beta \pi_{H k t+1}+(1-\chi) \pi_{H k t-1}+\kappa_{c} c_{k t}+\kappa_{y 0} y_{k t}+\kappa_{y 1} y_{k t-1}+\kappa_{s} s_{k \bar{k} t}
$$


where coefficients are

$$
\begin{aligned}
\chi & =\frac{\gamma(1-\omega)}{\gamma(1-\omega)+\omega(1+\gamma \beta)}, \kappa_{c}=\frac{(1-\omega)(1-\gamma \beta)(1-\gamma) \psi}{(\gamma(1-\omega)+\omega(1+\gamma \beta))(\psi+\epsilon) \sigma} \\
\kappa_{y 0} & =\frac{(1-\omega)(1-\gamma \beta)(1-\gamma)}{(\gamma(1-\omega)+\omega(1+\gamma \beta))(\psi+\epsilon)}, \kappa_{y 1}=\frac{\omega(1+\gamma \beta)(1-\gamma)}{\gamma(1-\omega)+\omega(1+\gamma \beta)} \delta \\
\kappa_{s} & =\frac{(1-\gamma \beta)(1-\gamma)(1-\omega) \psi\left(1-\alpha_{d}\right)}{(\gamma(1-\omega)+\omega(1+\gamma \beta))(\psi+\epsilon)}
\end{aligned}
$$

\section{A.2 Aggregate Demand}

Aggregation implies:

$$
Y_{k}=C_{H k}+C_{H k}^{* \bar{k}}+G_{H k}
$$

Its linearisaion up to second order yields

$$
\hat{Y}_{k s}+\frac{1}{2} \hat{Y}_{k s}^{2}=\theta \alpha_{d}\left(\hat{C}_{H k s}+\frac{1}{2} \hat{C}_{H k s}^{2}\right)+\theta \alpha_{n}\left(\hat{C}_{H k s}^{* \bar{k}}+\frac{1}{2} \hat{C}_{H k s}^{* \bar{k} 2}\right)+(1-\theta)\left(\hat{G}_{H k s}+\frac{1}{2} \hat{G}_{H k s}^{2}\right)
$$

On the other hand,

$$
C_{k}=C_{H k}+C_{H \bar{k}}
$$

and its linearisation up to second order yields:

$$
\hat{C}_{k}=\alpha_{d}\left(\hat{C}_{H k}+\frac{1}{2} \hat{C}_{H k}^{2}\right)+\alpha_{n}\left(\hat{C}_{H \bar{k}}+\frac{1}{2} \hat{C}_{H \bar{k}}^{2}\right)-\frac{1}{2} \hat{C}_{k}^{2}
$$

Now we substitute consumption into the aggregate demand and obtain:

$$
\begin{aligned}
\hat{Y}_{k} & =\theta \hat{C}_{k}+(1-\theta)\left(\hat{G}_{H k}+\frac{1}{2} \hat{G}_{H k}^{2}\right)+\theta \frac{1}{2} \hat{C}_{k}^{2}-\frac{1}{2} \hat{Y}_{k}^{2} \\
& +\theta \alpha_{n}\left(\hat{C}_{H k}^{* \bar{k}}-\hat{C}_{H \bar{k}}\right)+\frac{1}{2} \theta \alpha_{n}\left(\hat{C}_{H k}^{* \bar{k} 2}-\hat{C}_{H \bar{k}}^{2}\right)
\end{aligned}
$$

Now, the exact relationships between consumption are

$$
C_{H k}=\alpha_{d}\left(\frac{P_{H k}}{P_{k}}\right)^{-\eta} C_{k}
$$

We also have exact price indexes

$$
P_{k}=\left(\alpha_{d} P_{H k}^{1-\eta}+\alpha_{n} P_{H \bar{k}}^{1-\eta}\right)^{\frac{1}{1-\eta}}
$$

We linearise them and substitute in aggregate demand and assume symmetric countries. We finally obtain the linear aggregate demand relationship:

$$
\hat{Y}_{k}=\theta \alpha_{d} \hat{C}_{k}+\theta \alpha_{n} \hat{C}_{\bar{k}}^{*}+(1-\theta) \hat{G}_{k t}+2 \theta \eta \alpha_{d} \alpha_{n} \hat{S}_{k \bar{k}},
$$

and its second-order version:

$$
\begin{aligned}
\hat{Y}_{k} & =\theta \alpha_{d} \hat{C}_{k}+\theta \alpha_{n} \hat{C}_{\bar{k}}+(1-\theta) \hat{G}_{k}+2 \theta \eta \alpha_{d} \alpha_{n} \hat{S}_{k \bar{k}} \\
& +\frac{1}{2} \theta \alpha_{d} \hat{C}_{k}^{2}+\frac{1}{2} \theta \alpha_{n} \hat{C}_{\bar{k}}^{2}-\frac{1}{2} \hat{Y}_{k}^{2}+\frac{1}{2}(1-\theta) \hat{G}_{k}^{2}+\theta \alpha_{d} \alpha_{n} \eta \hat{S} \hat{C}_{\bar{k}}^{*}+\theta \alpha_{d} \alpha_{n} \eta \hat{S}_{k \bar{k}} \hat{C}_{k}
\end{aligned}
$$




\section{A.3 Risk sharing condition}

From the first-order conditions it folows that

$$
\beta \frac{u_{C}\left(C_{k t+1}\right)}{u_{C}\left(C_{k t}\right)} \frac{P_{k t}}{P_{k t+1}}=\frac{1}{1+i_{t}}, \beta \frac{u_{C}\left(C_{\bar{k} t+1}\right)}{u_{C}\left(C_{\bar{k} t}\right)} \frac{P_{\bar{k} t} E_{t}}{P_{\bar{k} t+1} E_{t+1}}=\frac{1}{\left(1+i_{t}\right)}
$$

Divide one by another to get

$$
\frac{u_{C}\left(C_{\bar{k} t}, \xi_{\bar{k} t}\right)}{Q_{t} u_{C}\left(C_{k t}, \xi_{k t}\right)}=\frac{u_{C}\left(C_{\bar{k} t+1}, \xi_{\bar{k} t+1}\right)}{u_{C}\left(C_{k t+1}, \xi_{k t+1}\right) Q_{t+1}}
$$

As we only consider temporary shocks we can iterate this forward to obtain:

$$
\frac{u_{C}\left(C_{\bar{k} t}, \xi_{\bar{k} t}\right)}{Q_{t} u_{C}\left(C_{k t}, \xi_{k t}\right)}=\frac{u_{C}\left(C_{\bar{k} t+m}, \xi_{\bar{k} t+m}\right)}{u_{C}\left(C_{k t+m}, \xi_{k t+m}\right) Q_{t+m}}=\vartheta_{t+m}
$$

where $m$ is large.

We want formula (40) to be written using the terms of term of trade, not the real exchange rate. Using $Q=\left(\alpha_{n}+\alpha_{d} S_{k \bar{k}}^{1-\eta}\right)^{\frac{1}{1-\eta}}\left(\alpha_{d}+\alpha_{n} S_{k \bar{k}}^{(1-\eta)}\right)^{-\frac{1}{1-\eta}}$ we obtain the linearised version of (40):

$$
\begin{aligned}
& \hat{C}_{k}=\hat{C}_{\bar{k}}+\sigma\left(\alpha_{d}-\alpha_{n}\right) \hat{S}_{k \bar{k}}+\frac{1}{2} \sigma\left(\alpha_{d}-\alpha_{n}\right)^{2} \hat{S}_{k \bar{k}}^{2}-\frac{1}{2} b \hat{C}_{k}^{2}-d \hat{C}_{k} \hat{\xi}_{a k}+\frac{1}{2} b \hat{C}_{\bar{k}}^{2} \\
& -\left(\alpha_{d}-\alpha_{n}\right) \hat{C}_{k} \hat{S}_{k \bar{k}}-\left(\alpha_{d}-\alpha_{n}\right) g \hat{\xi}_{k} \hat{S}_{k \bar{k}}-g\left(\hat{\xi}_{k}-\hat{\xi}_{\bar{k}}\right)-\frac{1}{2} g a \hat{\xi}_{k}^{2}+\frac{1}{2} g a \hat{\xi}_{\bar{k}}^{2}+d \hat{C}_{\bar{k}} \hat{\xi}_{\bar{k}}-\hat{\Theta}_{t+m}
\end{aligned}
$$

Here $\hat{\Theta}_{t+m}$ can be treated as a shock, because by sufficient iterating forward, we make $C_{k t+m}$, $Q_{t+m}$ close to terminal conditions, which are explicitly defined for jump variables $C_{j t+m}$, and relative prices.

\section{A.4 Useful relationships}

We can find $\hat{S}_{k \bar{k}}$ from the risk sharing condition (41) and substitute it into aggregate demand (37), $k \in\{a, b\}:$

$$
\begin{aligned}
\hat{Y}_{k} & =\theta \alpha_{d}\left(1+\frac{2 \alpha_{n} \eta}{\sigma\left(\alpha_{d}-\alpha_{n}\right)}\right) \hat{C}_{k}+\theta \alpha_{n}\left(1-\frac{2 \alpha_{d} \eta}{\sigma\left(\alpha_{d}-\alpha_{n}\right)}\right) \hat{C}_{\bar{k}}+(1-\theta) \hat{G}_{k} \\
& -\theta \alpha_{d} \alpha_{n} \eta\left(\alpha_{d}-\alpha_{n}\right) \hat{S}_{k \bar{k}}^{2}+\theta \alpha_{d}\left(\frac{\alpha_{n} \eta b}{\sigma\left(\alpha_{d}-\alpha_{n}\right)}+\frac{1}{2}\right) \hat{C}_{k}^{2}+\theta \alpha_{n}\left(\frac{1}{2}-\frac{\alpha_{d} \eta b}{\sigma\left(\alpha_{d}-\alpha_{n}\right)}\right) \hat{C}_{\bar{k}}^{2} \\
& +\frac{2 \theta \alpha_{d} \alpha_{n} \eta d}{\sigma\left(\alpha_{d}-\alpha_{n}\right)} \hat{C}_{k} \hat{\xi}_{k}+\frac{2 \theta \alpha_{d} \alpha_{n} \eta\left(\alpha_{d}-\alpha_{n}\right)}{\sigma\left(\alpha_{d}-\alpha_{n}\right)} g \hat{\xi}_{k} \hat{S}_{k \bar{k}}-\frac{1}{2} \hat{Y}_{k}^{2}+\frac{1}{2}(1-\theta) \hat{G}_{k}^{2} \\
& +\frac{2 \theta \alpha_{d} \alpha_{n} \eta g}{\sigma\left(\alpha_{d}-\alpha_{n}\right)}\left(\hat{\xi}_{k}-\hat{\xi}_{\bar{k}}\right)+\frac{1}{2} \frac{2 \theta \alpha_{d} \alpha_{n} \eta g a}{\sigma\left(\alpha_{d}-\alpha_{n}\right)} \hat{\xi}_{k}^{2}-\frac{1}{2} \frac{2 \theta \alpha_{d} \alpha_{n} \eta g a}{\sigma\left(\alpha_{d}-\alpha_{n}\right)} \hat{\xi}_{\bar{k}}^{2}-\frac{2 \theta \alpha_{d} \alpha_{n} \eta d}{\sigma\left(\alpha_{d}-\alpha_{n}\right)} \hat{C}_{\bar{k}} \hat{\xi}_{\bar{k}} \\
& +\theta \alpha_{d} \alpha_{n} \eta\left(1+\frac{2}{\sigma}\right) \hat{C}_{k} \hat{S}_{k \bar{k}}+\theta \alpha_{d} \alpha_{n} \eta \hat{S}_{k} \hat{C}_{\bar{k}}+\frac{2 \theta \alpha_{d} \alpha_{n} \eta}{\sigma\left(\alpha_{d}-\alpha_{n}\right)} \hat{\Theta}_{t+m}
\end{aligned}
$$

We can take the sum of relationships (42), written for both countries $a$ and $b$, and obtain the following formula

$$
\begin{aligned}
\left(\hat{C}_{a}+\hat{C}_{b}\right) & =\frac{1}{\theta}\left(\hat{Y}_{a}+\hat{Y}_{b}\right)-\frac{(1-\theta)}{\theta}\left(\hat{G}_{a}+\hat{G}_{b}\right)-\frac{1}{2}\left(\hat{C}_{a}^{2}+\hat{C}_{b}^{2}\right) \\
& +\frac{1}{2 \theta}\left(\hat{Y}_{a}^{2}+\hat{Y}_{b}^{2}\right)-\frac{1}{2} \frac{(1-\theta)}{\theta}\left(\hat{G}_{a}^{2}+\hat{G}_{b}^{2}\right)+2 \alpha_{d} \alpha_{n} \eta\left(\alpha_{d}-\alpha_{n}\right) \hat{S}_{a b}^{2} \\
& -2 \alpha_{d} \alpha_{n} \eta \frac{g}{\sigma}\left(\hat{\xi}_{a}-\hat{\xi}_{b}\right) \hat{S}_{a b}-\frac{2}{\sigma} \alpha_{d} \alpha_{n} \eta\left(\hat{C}_{a}-\hat{C}_{b}\right) \hat{S}_{a b}+t i p
\end{aligned}
$$


where tip are terms intependent of policy (including $\hat{\Theta}_{t+m}$ ). We use this formula later in the text.

\section{A.5 Government expenditures in flexible price equilibrium}

As the aggregate demand relationships, the labour market equilibrium condition and the risk sharing condition always hold along the dynamic path of adjustment, then we can differentiate them with respect to government expenditures, to obtain relationships which will be valid along the solution to the dynamic system.

We differentiate each of these relationships with respect to $G_{a}$ and $G_{b}$. We present equations differentiated with respect to $G_{a}$, and those differentiated with respect to $G_{b}$ can be written in a symmetric way:

$$
\begin{aligned}
\frac{\partial Y_{a}}{\partial G_{a}} & =\alpha_{d}\left(\frac{P_{H a}}{P_{a}}\right)^{-\eta} \frac{\partial C_{a}}{\partial G_{a}}+\alpha_{n}\left(\frac{P_{H a}^{* b}}{P_{b}^{* b}}\right)^{-\eta} \frac{\partial C_{b}}{\partial G_{a}} \\
& +\eta \alpha_{n} \alpha_{d} S_{a b}^{-\eta}\left(C_{a}\left(\frac{P_{H a}}{P_{a}}\right)^{1-2 \eta}+C_{b}\left(\frac{P_{H a}^{* b}}{P_{b}^{*}}\right)^{1-2 \eta}\right) \frac{\partial S_{a b}}{\partial G_{a}}+1 \\
\frac{\partial Y_{b}^{* b}}{\partial G_{a}} & =\alpha_{n}\left(\frac{P_{H b}}{P_{a}}\right)^{-\eta} \frac{\partial C_{a}}{\partial G_{a}}+\alpha_{d}\left(\frac{P_{H b}^{* b}}{P_{b}^{* b}}\right)^{-\eta} \frac{\partial C_{b}}{\partial G_{a}} \\
& -\alpha_{n} \eta \alpha_{d} S_{a b}^{-2+\eta}\left(C_{a}\left(\frac{P_{H b}}{P_{a}}\right)^{1-2 \eta}+C_{b}\left(\frac{P_{H b}^{* b}}{P_{b}^{*}}\right)^{1-2 \eta}\right) \frac{\partial S_{a b}}{\partial G_{a}}
\end{aligned}
$$

Differentiation of the risk sharing condition yields:

$$
\begin{aligned}
\frac{\partial C_{b t}}{\partial G_{a}} & =\left(\left(\alpha_{d}\left(\alpha_{d} S_{a b}^{(1-\eta)}+\alpha_{n}^{b}\right)^{-1}-\left(\alpha_{d}+\alpha_{n} S_{a b}^{1-\eta}\right)^{-1} \alpha_{n}\right) S_{a b}^{-\eta} \frac{\partial S_{a b}}{\partial G_{a}} \frac{u_{C}\left(C_{a t}, \xi_{a t}\right)}{u_{C C}\left(C_{b t}, \xi_{b t}\right)}\right. \\
& \left.+\frac{u_{C C}\left(C_{a t}, \xi_{a t}\right)}{u_{C C}\left(C_{b t}, \xi_{b t}\right)} \frac{\partial C_{a t}}{\partial G_{a}}\right) \vartheta_{a b}\left(\alpha_{d} S_{a b}^{(1-\eta)}+\alpha_{n}\right)^{\frac{1}{1-\eta}}\left(\alpha_{d}+\alpha_{n} S_{a b}^{1-\eta}\right)^{-\frac{1}{1-\eta}}
\end{aligned}
$$

Differention of the labour market equilibrium condition yields:

$$
\begin{aligned}
& \frac{\mu^{w}(1-\tau)}{\mu_{t}} \frac{\partial C_{a}}{\partial G_{a}} u_{C C}\left(C_{a t}, \xi_{a t}\right)=\frac{P_{a}}{P_{H a}} \frac{\partial Y_{a}}{\partial G_{a}} v_{y y}\left(Y_{a t}, \xi_{a t}\right)+S_{a b}^{-\eta}\left(\frac{P_{a}}{P_{H a}}\right)^{\eta} \alpha_{n} \frac{\partial S_{a b}}{\partial G_{a}} v_{y}\left(Y_{a t}, \xi_{a t}\right) \\
& \frac{\mu^{w}(1-\tau)}{\mu_{t}} \frac{\partial C_{b}}{\partial G_{a}} u_{C C}\left(C_{b t}, \xi_{b t}\right)=\frac{P_{b}}{P_{H b}} \frac{\partial Y_{b}}{\partial G_{a}} v_{y y}\left(Y_{b t}, \xi_{b t}\right)-S_{a b}^{-2+\eta}\left(\frac{P_{b}}{P_{H b}^{b}}\right)^{\eta} \alpha_{n} \frac{\partial S_{a b}}{\partial G_{a}} v_{y}\left(Y_{b t}, \xi_{b t}\right)
\end{aligned}
$$

These five relationships can be solved with respect to five unknowns: $\frac{\partial S_{a b}}{\partial G_{a}}, \frac{\partial Y_{a}}{\partial G_{a}}, \frac{\partial Y_{b}}{\partial G_{a}}, \frac{\partial C_{a}}{\partial G_{a}}, \frac{\partial C_{b}}{\partial G_{a}}$ as functions of $C_{a}, C_{b}, S_{a b}$.

Additionally, in equilibrium (including flexible-price equilibrium), a socially optimal fiscal policy should aim to maximise union-wide social welfare, subject to static constraints (aggregate demand, risk sharing, labour market equilibrium condition). As derivatives of these constraints are all equal to zero along the dynamic solution then

$$
\begin{aligned}
& \frac{\partial}{\partial G_{a}}\left[u\left(C_{a}, \xi_{a}\right)+f\left(G_{a}, \xi_{a}\right)-v\left(Y_{a}, \xi_{a}\right)+u\left(C_{b}, \xi_{b}\right)+f\left(G_{b}, \xi_{b}\right)-v\left(Y_{b}, \xi_{b}\right)\right] \\
& =u_{C}\left(C_{a}, \xi_{a}\right) \frac{\partial C_{a}}{\partial G_{a}}+f_{G_{a}}\left(G_{a}, \xi_{a}\right)-v_{y}\left(Y_{a}, \xi_{a}\right) \frac{\partial Y_{a}}{\partial G_{a}}+u_{C}\left(C_{b}, \xi_{b}\right) \frac{\partial C_{b}}{\partial G_{a}}-v_{y}\left(Y_{b}, \xi_{b}\right) \frac{\partial Y_{b}}{\partial G_{a}}=0
\end{aligned}
$$


We can substitute formulae for $\frac{\partial Y_{a}}{\partial G_{a}}, \frac{\partial Y_{b}}{\partial G_{a}}, \frac{\partial C_{a}}{\partial G_{a}}, \frac{\partial C_{b}}{\partial G_{a}}$. The resulting formula can be linearised around steady state to yield:

$$
g_{k \xi} \hat{\xi}_{k}+g_{\bar{k} \xi} \hat{\xi}_{\bar{k}}=\hat{G}_{k}^{n}+g_{k s} \hat{S}_{k \bar{k}}^{n}+g_{k c} \hat{C}_{k}^{n}+g_{\bar{k} c} \hat{C}_{\bar{k}}^{n}+g_{k y} \hat{Y}_{k}^{n}+g_{\bar{k} y} \hat{Y}_{\bar{k}}^{n}
$$

in the flexible-price equilibrium, labelled with superscript ${ }^{n}$. In this formula

$$
\begin{aligned}
g_{k \xi}= & 1+\frac{\sigma\left(\psi+\theta \sigma-\theta \alpha_{n}(\psi+\theta \sigma)-2 \alpha_{n} \alpha_{d} \theta(\sigma-\eta)(1-\theta)\right)}{(\theta \sigma+\psi)\left(-4 \alpha_{d} \theta(\sigma-\eta)\left(1-\alpha_{d}\right)+\psi+\theta \sigma\right)} \\
g_{\bar{k} \xi}= & -\frac{2 \theta \sigma \alpha_{n} \alpha_{d}(\sigma-\eta)(1-\theta)+\theta \alpha_{d}(\psi+\theta \sigma)}{(\theta \sigma+\psi)\left(-4 \alpha_{d} \theta(\sigma-\eta) \alpha_{n}+\psi+\theta \sigma\right)} \\
g_{k s}= & -\frac{2 \sigma \alpha_{d} \alpha_{n} \theta \eta}{\left(-4 \theta \alpha_{d} \alpha_{n}(\sigma-\eta)+\psi+\theta \sigma\right)} \\
g_{k c}= & \frac{\theta \sigma \alpha_{n}\left(2 \theta(\sigma-\eta) \alpha_{d}-(\psi+\theta \sigma)\right)}{(\theta \sigma+\psi)\left(-4 \theta \alpha_{d} \alpha_{n}(\sigma-\eta)+\psi+\theta \sigma\right)} \\
g_{\bar{k} c}= & \frac{\theta \sigma \alpha_{d}\left(2 \theta(\sigma-\eta) \alpha_{n}-(\psi+\theta \sigma)\right)}{(\theta \sigma+\psi)\left(-4 \theta \alpha_{d} \alpha_{n}(\sigma-\eta)+\psi+\theta \sigma\right)} \\
g_{k y}= & \frac{\sigma\left(\psi+\theta \sigma-2 \theta(\sigma-\eta) \alpha_{d} \alpha_{n}\right)}{(\theta \sigma+\psi)\left(-4 \alpha_{d} \alpha_{n} \theta(\sigma-\eta)+\psi+\theta \sigma\right)} \\
g_{\bar{k} y}= & -\frac{2 \theta \sigma \alpha_{n} \alpha_{d}(\sigma-\eta)}{(\theta \sigma+\psi)\left(-4 \alpha_{d} \alpha_{n} \theta(\sigma-\eta)+\psi+\theta \sigma\right)}
\end{aligned}
$$

\section{B Social loss function}

The one-period social welfare function can be obtained by linearisation of the one-period welfare function in (1) up to the second-order terms (we assume symmetry):

$$
\begin{aligned}
\mathcal{W}_{a}+\mathcal{W}_{b} & =u_{C} \theta\left[\hat{C}_{a}+\hat{C}_{b}+\frac{1}{2}\left(1-\frac{1}{\sigma}\right)\left(\hat{C}_{a}^{2}+\hat{C}_{b}^{2}\right)+\frac{u_{C \xi}}{u_{C}}\left(\hat{C}_{a} \hat{\xi}_{a}+\hat{C}_{b} \hat{\xi}_{b}\right)\right] \\
& +G f_{G}\left[\left(\hat{G}_{a}+\hat{G}_{b}\right)+\frac{1}{2}\left(1-\frac{1}{\sigma}\right)\left(\hat{G}_{a}^{2}+\hat{G}_{b}^{2}\right)+\frac{f_{G \xi}}{f_{G}}\left(\hat{G}_{a} \hat{\xi}_{a}+\hat{G}_{b} \hat{\xi}_{b}\right)\right] \\
& -v_{y}\left[\left(\hat{Y}_{a}+\hat{Y}_{b}\right)+\frac{v_{y \xi}}{v_{y}}\left(\hat{Y}_{a} \hat{\xi}_{a}+\hat{Y}_{b} \hat{\xi}_{b}\right)\right. \\
& \left.+\frac{1}{2}\left(1+\frac{1}{\psi}\right)\left(\hat{Y}_{a}^{2}+\hat{Y}_{b}^{2}\right)+\frac{1}{2}\left(\frac{1}{\psi}+\frac{1}{\epsilon}\right)\left(\operatorname{var}_{z} \hat{y}_{a}(z)+\operatorname{var}_{z} \hat{y}_{b}(z)\right)\right]+t i p
\end{aligned}
$$

where we assumed $\sigma=-u_{C}(C, 1) / u_{C C}(C, 1) C=-f_{G}(G, 1) / f_{G G}(G, 1) G$.

We need to find an expression for $v_{y} / u_{C} C$ and $f_{G} / u_{C} C$. The first condition follows from the steady state condition

$$
\frac{v_{y}}{u_{C}}=\frac{\mu^{w}(1-\tau)}{\mu}
$$

and in order to derive the second expression we closely follow Beetsma and Jensen (2003). The second steady state relationship is

$$
\frac{f_{G}}{u_{C}}=\frac{\psi \mu^{w}(1-\tau) / \mu+\theta \sigma}{(\psi+\theta \sigma)}
$$

and it is obtained from formula (44), where all values are taken at steady state. 
We now need to derive a formula for $\operatorname{var}_{z} \hat{y}(z)$, along the lines of Rotemberg and Woodford (1997) and Steinsson (2003). This leads to the formula (for country $k$ ):

$$
\begin{aligned}
\operatorname{var}_{z} \hat{y}_{k t}(z) & =\frac{\epsilon^{2}}{(1-\gamma \beta)}\left(\frac{\gamma}{1-\gamma} \pi_{H k t}^{2}+\frac{\omega}{(1-\omega)} \frac{1}{(1-\gamma)}\left(\Delta \pi_{H k t}\right)^{2}\right. \\
& \left.+\frac{\omega}{(1-\omega)}(1-\gamma) \delta^{2} y_{k t-1}^{2}+\frac{2 \omega}{(1-\omega)} \delta y_{k t-1} \Delta \pi_{H k t}\right)
\end{aligned}
$$

We now substitute consumption from formula (43) into (46) and, using (47) and (48), obtain:

$$
\begin{aligned}
\mathcal{W}_{a}+\mathcal{W}_{b} & =u_{C} C\left[\frac{1}{\theta}\left(1-\frac{\mu^{w}(1-\tau)}{\mu}\right)\left(\hat{Y}_{a}+\hat{Y}_{b}\right)-\frac{1}{2} \frac{1}{\sigma}\left(\hat{C}_{a}^{2}+\hat{C}_{b}^{2}\right)\right. \\
& +\frac{(1-\theta)}{\theta\left(1+\sigma \frac{\theta}{\psi}\right)}\left(\frac{\mu^{w}(1-\tau)}{\mu}-1\right)\left(\hat{G}_{H a}+\hat{G}_{H b}\right) \\
& +\frac{1}{2} \frac{1}{\theta}\left(1-\frac{\mu^{w}(1-\tau)}{\mu}\left(1+\frac{1}{\psi}\right)\right)\left(\hat{Y}_{a}^{2}+\hat{Y}_{b}^{2}\right)+2 \alpha_{n} \eta \alpha_{d}\left(\alpha_{d}-\alpha_{n}\right) \hat{S}_{a b}^{2} \\
& -\frac{2}{\sigma} \alpha_{n} \eta \alpha_{d}\left(\hat{C}_{a}-\hat{C}_{b}\right) \hat{S}_{a b}+2 \alpha_{n} \eta \alpha_{d} \frac{u_{C \xi}}{u_{C}}\left(\hat{\xi}_{a}-\hat{\xi}_{b}\right) \hat{S}_{a b} \\
& +\frac{1}{2} \frac{(1-\theta)}{\theta}\left(\frac{\frac{\mu^{w}(1-\tau)}{\mu}+\sigma \frac{\theta}{\psi}}{\left(1+\sigma \frac{\theta}{\psi}\right)}\left(1-\frac{1}{\sigma}\right)-1\right)\left(\hat{G}_{H a}^{2}+\hat{G}_{H b}^{2}\right) \\
& +\frac{u_{C \xi}}{u_{C}}\left(\hat{C}_{a} \hat{\xi}_{a}+\hat{C}_{b} \hat{\xi}_{b}\right)+\frac{\mu^{w}}{\theta \mu}(1-\tau) \frac{v_{y \xi}}{v_{y}}\left(\hat{Y}_{a} \hat{\xi}_{a}+\hat{Y}_{b} \hat{\xi}_{b}\right) \\
& +\frac{(1-\theta)}{\theta} \frac{\mu^{w}(1-\tau)}{\mu}+\sigma \frac{\theta}{\psi} \frac{f_{G \xi}}{f_{G}}\left(\hat{G}_{a} \hat{\xi}_{a}+\hat{G}_{b} \hat{\xi}_{b}\right) \\
& \left.-\frac{\mu^{w}(1-\tau)}{\theta \mu} V_{z} \hat{y}_{a}(z) \frac{1}{2}\left(\frac{1}{\psi}+\frac{1}{\epsilon}\right)-\frac{\mu^{w}(1-\tau)}{\theta \mu} V_{z} \hat{y}_{b}(z) \frac{1}{2}\left(\frac{1}{\psi}+\frac{1}{\epsilon}\right)\right]+\operatorname{tip}(3)
\end{aligned}
$$

Now, if the government removes monopolistic distortions and distortions from labour income taxation in the steady state using a subsidy $\mu^{w}=\frac{\mu}{(1-\tau)}$, then the welfare function does not contain 
linear terms. The expression for welfare simplifies to:

$$
\begin{aligned}
\mathcal{W}_{a}+\mathcal{W}_{b} & =-u_{C} C \mathcal{U}_{s}=-u_{C} C \frac{1}{\theta}\left[\frac{\theta}{2 \sigma}\left(\left(\hat{C}_{a}-\hat{C}_{a}^{n}\right)^{2}+\left(\hat{C}_{b}-\hat{C}_{b}^{n}\right)^{2}\right)\right. \\
& +\frac{1}{2 \psi}\left(\left(\hat{Y}_{a}-\hat{Y}_{a}^{n}\right)^{2}+\left(\hat{Y}_{b}-\hat{Y}_{b}^{n}\right)^{2}\right)+\frac{(1-\theta)}{2 \sigma}\left(\left(G_{a}-G_{a}^{n}\right)^{2}+\left(G_{b}-G_{b}^{n}\right)^{2}\right) \\
& -2 \alpha_{n} \eta \alpha_{d}\left(\alpha_{d}-\alpha_{n}\right)\left(\hat{S}_{a b}-\hat{S}_{a b}^{n}\right)^{2}+\frac{2 \theta \alpha_{n} \eta \alpha_{d}}{\sigma}\left(\hat{S}_{a b}-\hat{S}_{a b}^{n}\right)\left(\hat{C}_{a}-\hat{C}_{a}^{n}\right) \\
& -\frac{2 \theta \alpha_{n} \eta \alpha_{d}}{\sigma}\left(\hat{S}_{a b}-\hat{S}_{a b}^{n}\right)\left(\hat{C}_{b}-\hat{C}_{b}^{n}\right) \\
& -\frac{\theta}{\sigma(\psi+\sigma)} \hat{C}_{a}\left[\sigma \hat{Y}_{a}^{n}-\sigma \hat{C}_{a}^{n}+\alpha_{n}\left(\psi \sigma-2 \eta \alpha_{d}(\psi+\sigma)\right) \hat{S}_{a b}^{n}\right] \\
& -\frac{\theta}{\sigma(\psi+\sigma)} \hat{C}_{b}\left[\sigma \hat{Y}_{b}^{n}-\sigma \hat{C}_{b}^{n}-\alpha_{n}\left(\psi \sigma-2(\psi+\sigma) \eta \alpha_{d}\right) \hat{S}_{a b}^{n}\right] \\
& +\frac{1}{(\psi+\sigma)} \hat{Y}_{a}\left[\hat{Y}_{a}^{n}-\hat{C}_{a}^{n}-\alpha_{n} \sigma \hat{S}_{a b}^{n}\right]+\frac{1}{(\psi+\sigma)} \hat{Y}_{b}\left[\hat{Y}_{b}^{n}-\hat{C}_{b}^{n}+\alpha_{n} \sigma \hat{S}_{a b}^{n}\right] \\
& -\frac{(1-\theta)}{(\psi+\sigma)} \hat{G}_{a}\left[\hat{Y}_{a}^{n}-G_{a}^{n}+\psi \alpha_{n} \hat{S}_{a b}^{n}\right]-\frac{(1-\theta)}{(\psi+\sigma)} \hat{G}_{b}\left[\hat{Y}_{b}^{n}-G_{b}^{n}-\psi \alpha_{n} \hat{S}_{a b}^{n}\right] \\
& -\frac{2 \theta \eta \alpha_{n} \alpha_{d}}{(\psi+\sigma)} \hat{S}_{a b}\left[2\left(\left(\alpha_{d}-\alpha_{n}\right)(\psi+\sigma)+\alpha_{n} \psi\right) \hat{S}_{a b}^{n}+\left(\hat{Y}_{a}^{n}-\hat{Y}_{b}^{n}\right)-\left(\hat{C}_{a}^{n}-\hat{C}_{b}^{n}\right)\right] \\
& \left.+V_{z} \hat{y}_{a}(z) \frac{1}{2}\left(\frac{1}{\psi}+\frac{1}{\epsilon}\right)+V_{z} \hat{y}_{b}(z) \frac{1}{2}\left(\frac{1}{\psi}+\frac{1}{\epsilon}\right)\right]+t i p(3)
\end{aligned}
$$

where we substituted natural rates for taste/technology shocks, using formula (17). This is formula (27) in the main text.

\section{Compensating Consumption}

Having computed the social loss in stochastic equilibrium for an optimal policy, we can give an interpretation of losses in terms of 'real world' variables. This optimal policy results in stochastic volatility $\mathcal{W}$ of the key variables and steady state level of consumption $C$. We now find percent reduction in steady-state consumption under the benchmark policy that makes household as well off as under our optimal policy. This benchmark policy is with no stochastic volatility, but results in a new steady state level of consumption of $C+\Omega C$. We determine the percentage change in consumption $\Omega$ such that we have the same level of welfare under both policies. A form of utility function is not assumed known, but $u_{C}(C, 1) / u_{C C}(C, 1) C=-\sigma$ in the steady state.

Formula (49) shows that the level of the welfare (to a second order approximation) of a social planner in a monetary union of two identical countries can be written as

$$
\begin{aligned}
L & =\mathcal{E}_{t} \sum_{s=t}^{\infty} \beta^{s-t}\left(2 u(C, 1)+2 f(G, 1)-2 v(Y, 1)-u_{C}(C, 1) C \mathcal{U}_{s}\right) \\
& =\frac{2}{1-\beta}(u(C, 1)+f(G, 1)-v(Y, 1))-C u_{C}(C, 1) \mathcal{E}_{t} \sum_{s=t}^{\infty} \beta^{s-t} \mathcal{U}_{s}
\end{aligned}
$$

where $\mathcal{U}$ is intra-period value of the social welfare function and $C, G$ and $Y$ refer to steady state levels of consumption, government spending and output. Under the benchmark policy there is no 
volatility, $\mathcal{U}_{s} \equiv 0$, so:

$$
\begin{aligned}
L_{0} & =\frac{2}{1-\beta}(u(C+\Omega C, 1)+f(G, 1)-v(Y, 1)) \\
& =\frac{2}{1-\beta}\left(u(C, 1) C \Omega\left(1-\frac{\Omega}{2 \sigma}\right)+u(C, 1)+f(G, 1)-v(Y, 1)\right)+o(\Omega C)^{3}
\end{aligned}
$$

An individual will be indifferent between these two policies when

$$
\Omega\left(1-\frac{\Omega}{2 \sigma}\right)+\frac{(1-\beta)}{2} \mathcal{E}_{t} \sum_{s=t}^{\infty} \beta^{s-t} \mathcal{U}_{s}=0
$$

which is an equation for $\Omega$. The relevant solution is:

$$
\Omega=\sigma\left(1-\sqrt{1+\frac{(1-\beta)}{\sigma} \mathcal{E}_{t} \sum_{s=t}^{\infty} \beta^{s-t} \mathcal{U}_{s}}\right)
$$

We find $\mathcal{E}_{t} \sum_{s=t}^{\infty} \beta^{s-t} \mathcal{U}_{s}$ using the procedure outlined in Currie and Levine (1993), see the working paper version of this paper for details (Kirsanova, Satchi, Vines, and Wren-Lewis (2004)).

\section{Policy Game}

\section{D.1 Canonical Form of the Model}

The system (18)-(24) can be written in matrix form as:

$$
\Omega Z_{t+1}=\mathrm{A} Z_{t}+\mathrm{B} U_{t}^{F}+\mathrm{D} U_{t}^{M}+\delta_{t+1}
$$

where $Z_{t}=\left(Y_{t}^{\prime}, X_{t}^{\prime}\right)^{\prime}, Y_{t}$ is a vector of predetermined states and $X_{t}$ is a vector of non-predetermined states; $U_{t}^{M}$ is monetary instrument and $U_{t}^{F}=\left(U_{t}^{A F^{\prime}}, U_{t}^{A F^{\prime}}\right)^{\prime}$ is vector of fiscal instruments for the two countries; $\delta_{t}$ is a vector of disturbances. If $\Omega$ is invertible, we multiply both sides by $\Omega^{-1}$ to come to the canonical form representation:

$$
Z_{t+1}=\mathrm{A} Z_{t}+\mathrm{B} U_{t}^{F}+\mathrm{D} U_{t}^{M}+\nu_{t+1}
$$

The central banks's loss function (25) is written in terms of goal variables, $G_{t}^{M}$, which can be linked to the state variable $Z_{t}$, as $G_{t}^{M}=\mathcal{C}^{M} Z_{t}$, so that the welfare criterion (25) can be presented as:

$$
\begin{aligned}
& \min _{\left\{U_{s}^{M}\right\}_{s=t}^{\infty}} \frac{1}{2} \mathcal{E}_{t} \sum_{s=t}^{\infty} \rho^{s-t} G_{s}^{M \prime} Q^{M} G_{s}^{M} \\
= & \min _{\left\{U_{s}^{M}\right\}_{s=t}^{\infty}} \frac{1}{2} \mathcal{E}_{t} \sum_{s=t}^{\infty} \beta^{s-t}\left[Z_{s}^{\prime} \mathcal{Q}^{M} Z_{s}+2 Z_{s}^{\prime} \mathcal{P}^{M} U_{s}^{M}+U_{s}^{M \prime} \mathcal{R}^{M} U_{s}^{M}\right]
\end{aligned}
$$

Optimisation problem of fiscal authorities in country $A$ can be written as (see formula (26)):

$$
\begin{aligned}
& \min _{\left\{U_{s}^{A F}\right\}_{s=t}^{\infty}} \frac{1}{2} \mathcal{E}_{t} \sum_{s=t}^{\infty} \beta^{s-t} G_{s}^{A F^{\prime}} Q^{A F} G_{s}^{A F} \\
= & \frac{1}{2} \mathcal{E}_{t} \sum_{s=t}^{\infty} \beta^{s-t}\left[Z_{s}^{\prime} \mathcal{Q}^{A F} Z_{s}+Z_{s}^{\prime} \mathcal{P}^{A F} U_{s}^{F}+U_{s}^{F^{\prime}} \mathcal{P}^{A F^{\prime}} Z_{s}+U_{s}^{F \prime} \mathcal{R}^{A F} U_{s}^{F}\right]
\end{aligned}
$$


In country $B$ the problem is symmetric with $\mathcal{Q}^{B F}, \mathcal{P}^{B F}$ and $\mathcal{R}^{B F}$.

We solve the problem of finding the optimal path for instruments $\left\{U_{s}^{M}, U_{s}^{A F}, U_{s}^{B F}\right\}_{s=t}^{\infty}$ such that they would minimise criteria (52) and (53) subject to the constraint (51) and information structure.

\section{D.2 The Follower's Optimisation Problem}

We modify the procedure, explained in Blake and Kirsanova (2003) to account for the two Nash fiscal authorities. For more details see also Appendix to Kirsanova, Satchi, Vines, and Wren-Lewis (2004).

In the world where authorities cannot precommit, and in a linear-quadratic setup, the optimal solutions belong to the class of linear feedback rules. Being a follower, the fiscal authorities observe monetary authorities' actions and react to them, $U_{t}^{A F}=-F^{A F} Y_{t}-L^{A} U_{t}^{M}, U_{t}^{B F}=-F^{B F} Y_{t}-$ $L^{B} U_{t}^{M}$. However, they do not respond to each other's actions, as this is a Nash game.

Solution of this game requires representation of the private sector's beliefs about monetary authorities as $U_{t}^{M}=-F^{M} Y_{t}$, so their decisions can be represented as $X_{t}=-N Y_{t}$, see Blanchard and Kahn (1980). Then it is possible to represent $X_{t}=-J Y_{t}-K^{A F} U_{t}^{A F}-K^{B F} U_{t}^{B F}-K^{M} U_{t}^{M}$, as did Oudiz and Sachs (1985).

The cost-to-go from time $t$ for country $A$ satisfies the following dynamic programming equation:

$$
W_{t}=\frac{1}{2}\left(Z_{s}^{\prime} \mathcal{Q}^{A F} Z_{s}+Z_{s}^{\prime} \mathcal{P}^{A F} U_{s}^{F}+U_{s}^{F^{\prime}} \mathcal{P}^{A F^{\prime}} Z_{s}+U_{s}^{F^{\prime}} \mathcal{R}^{A F} U_{s}^{F}\right)+\beta W_{t+1}
$$

that can be brought into a recursive form for matrix $\mathcal{S}_{A}^{t}$ :

$$
\begin{aligned}
\mathcal{S}_{A}^{t} & =Q^{s}-\left(F^{A F}-L F^{M}\right)^{\prime} U_{F}^{s \prime}-U_{F}^{s}\left(F^{A F}-L F^{M}\right) \\
& +\left(F^{A F}-L F^{M}\right)^{\prime} R^{s}\left(F^{A F}-L F^{M}\right)-U_{M}^{s} F^{M}-F^{M \prime} U_{M}^{s \prime} \\
& +\left(F^{A F}-L F^{M}\right)^{\prime} P_{s}^{\prime} F^{M}+F^{M \prime} P_{s}\left(F^{A F}-L F^{M}\right)+F^{M \prime} T_{s} F^{M} \\
& -\beta\left[\left(\left(A_{11}-B_{12} F^{B F}\right)^{\prime}-\left(J-K^{B F} F^{B F}\right)^{\prime} A_{12}^{\prime}\right)\right. \\
& -\left(F^{A F}-L F^{M}\right)^{\prime}\left(B_{11}-A_{12} K^{A F}\right)^{\prime}-F^{M \prime}\left(\left(D_{1}-B_{12} L\right)^{\prime}\right. \\
& \left.\left.-\left(K^{M}-K^{B F} L\right)^{\prime} A_{12}^{\prime}\right)\right] \mathcal{S}_{A}^{t+1}\left[\left(B_{11}-A_{12} K^{A F}\right)\left(F^{A F}-L F^{M}\right)\right. \\
& -\left(\left(A_{11}-B_{12} F^{B F}\right)-A_{12}\left(J-K^{B F} F^{B F}\right)\right) \\
& \left.+\left(\left(D_{1}-B_{12} L\right)-A_{12}\left(K^{M}-K^{B F} L\right)\right) F^{M}\right]
\end{aligned}
$$

and we can obtain an update on $F^{A F}$ and $L^{B}$ :

$$
\begin{aligned}
F^{A F} & \left.=\left(R^{s}+\beta\left(B_{11}-A_{12} K^{A F}\right)^{\prime} \mathcal{S}_{A}^{t+1}\left(B_{11}-A_{12} K^{A F}\right)\right)\right)^{-1}\left(U_{F}^{s \prime}+\right. \\
& +\beta\left(B_{11}-A_{12} K^{A F}\right)^{\prime} \mathcal{S}_{A}^{t+1}\left(A_{11}-B_{12} F^{B F}-A_{12}\left(J-K^{B F} F^{B F}\right)\right) \\
L & \left.=\left(R^{s}+\beta\left(B_{11}-A_{12} K^{A F}\right)^{\prime} \mathcal{S}_{A}^{t+1}\left(B_{11}-A_{12} K^{A F}\right)\right)\right)^{-1}\left(P_{s}^{\prime}+\right. \\
& +\beta\left(B_{11}-A_{12} K^{A F}\right)^{\prime} \mathcal{S}_{A}^{t+1}\left(\left(D_{1}-B_{12} L\right)-A_{12}\left(K^{M}-K^{B F} L\right)\right)
\end{aligned}
$$

where all matrices can be obtained from those used in (52), (53) and (51). Similar formulae can be derived for the other country, country $B$. 


\section{D.3 The Leader's Optimisation Problem}

Formally, $G_{t}^{M}=\mathcal{C}^{M}\left[Z_{t}^{\prime}, U_{t}^{F^{\prime}}, U_{t}^{M \prime}\right]^{\prime}$, and when monetary authority moves it knows the fiscal authorities' reaction functions, $U_{t}^{A F}=-F^{A F} Y_{t}-L^{A} U_{t}^{M}, U_{t}^{B F}=-F^{B F} Y_{t}-L^{B} U_{t}^{M}$. Therefore,

$$
G_{t}^{M}=\tilde{\mathcal{C}}^{M}\left[Z_{t}^{\prime}, U_{t}^{M \prime}\right]^{\prime}
$$

Their welfare criterion (52) can now be rewritten:

$$
\begin{aligned}
& \frac{1}{2} \mathcal{E}_{t} \sum_{s=t}^{\infty} \beta^{s-t}\left(G_{s}^{M \prime} Q^{M} G_{s}^{M}\right) \\
= & \frac{1}{2} \mathcal{E}_{t} \sum_{s=t}^{\infty} \beta^{s-t}\left(Z_{s}^{\prime} \mathcal{Q}^{M} Z_{s}+Z_{s}^{\prime} \mathcal{P}^{M} U_{s}^{M}+U_{s}^{M \prime} \mathcal{P}^{M \prime} Z_{s}+U_{s}^{F \prime} \mathcal{R}^{M} U_{s}^{M}\right)
\end{aligned}
$$

Constraint (51) is also modified:

$$
Z_{t+1}=\left(\mathrm{A}-\mathrm{B}\left[F^{F^{\prime}}, 0\right]^{\prime}\right) Z_{t}+(\mathrm{D}-\mathrm{B} L) U_{t}^{M}+\nu_{t+1}
$$

Optimisation problem (59) and (60) is a standard problem of discretionary optimisation and solution algorithm is well known, see Oudiz and Sachs (1985), or Söderlind (1999) for a recent version.

\section{D.4 Iterative Procedure}

Finally, the problem can be solved iteratively. We start with initial guess of $F_{(0)}^{M}, F_{(0)}^{F}$ and $L_{(0)}$. We substitute these matrices into the routine which solves for the optimal response of fiscal authorities, (56)-(55) and similar equations for country $B$. We will improve $F_{(1)}^{F}$ and $L_{(1)}$ but not $F_{(0)}^{M}$. We then take into account the reaction of fiscal authorities and compute new matrices in equation (60), updated target variables (58) and solve the problem for monetary authorities. This will give us a new best reaction $F_{(1)}^{M}$. Then we again solve the problem for the fiscal authorities to update $F_{(2)}^{F}$ and $L_{(2)}$ and so on. We are unaware of any formal proofs of convergence of this type of the procedure, although the fixed point property was proved for the one-dimentional case. Our experience shows that relative to the standard Oudiz and Sachs procedure for a single policymaker, this problem requires more iterations to converge, but overall performance is satisfactory. 